\title{
Global projections of drought hazard in a warming climate: a prime for disaster risk management
}

\author{
Hugo Carrão ${ }^{1} \cdot$ Gustavo Naumann $^{1} \cdot$ Paulo Barbosa $^{1}$
}

Received: 27 September 2016 / Accepted: 20 April 2017 / Published online: 1 June 2017

(c) The Author(s) 2017. This article is an open access publication

\begin{abstract}
Projections of drought hazard $(d H)$ changes have been mapped from five bias-corrected climate models and analyzed at the global level under three representative concentration pathways (RCPs). The motivation for this study is the observation that drought risk is increasing globally and the effective regulation of prevention and adaptation measures depends on $d H$ magnitude and its distribution for the future. Based on the Weighted Anomaly of Standardized Precipitation index, $d H$ changes have been assessed for mid-(2021-2050) and late-century (20712099). With a few exceptions, results show a likely increase in global $d H$ between the historical years (1971-2000) and both future time periods under all RCPs. Notwithstanding this worsening trend, it was found that projections of $d H$ changes for most regions are neither robust nor significant in the near-future. By the end of the century, greater increases are projected for RCPs describing stronger radiative forcing. Under RCP8.5, statistically significant $d H$
\end{abstract}

This research received support from the EUROCLIMA regional cooperation program between the European Union (European Commission; DG DEVCO) and Latin America. Research by Gustavo Naumann was funded by the European Union Seventh Framework Programme FP7/2007-2013 under Grant Agreement No. 603864 (HELIX: High-End cLimate Impacts and eXtremes). The authors are grateful to the modeling groups and the CMIP projects for making the model data available, and acknowledge the ISI-MIP project for providing the bias-corrected datasets.

Paulo Barbosa

paulo.barbosa@ec.europa.eu

Hugo Carrão

hugo.carrao@gmail.com

1 European Commission, Joint Research Centre (JRC), Directorate for Space, Security and Migration, Disaster Risk Management Unit, Via E. Fermi 2749, I-21027 Ispra, VA, Italy changes emerge for global Mediterranean ecosystems and the Amazon region, which are identified as possible hotspots for future water security issues. Taken together, projections of $d H$ changes point towards two dilemmas: (1) in the near-term, stake-holders are left worrying about projected increasing $d H$ over large regions, but lack of actionable model agreement to take effective decisions related to local prevention and adaptation initiatives; (2) in the long-term, models demonstrate remarkable agreement, but stake-holders lack actionable knowledge to manage potential impacts far distant from actual human-dominated environments. We conclude that the major challenge for risk management is not to adapt human populations or their activities to $d H$ changes, but to progress on global initiatives that mitigate their impacts in the whole carbon cycle by late-century.

Keywords Drought hazard · Risk management · Global warming $\cdot$ CMIP5 models $\cdot$ ISI-MIP project $\cdot$ RCP scenarios

\section{Introduction}

Drought is a recurring and extreme climate event that is originated by a temporary water deficit and may be related to a lack of precipitation, soil moisture, streamflow, or any combination of the three taking place at the same time (Wilhite and Glantz 1985). Drought differs from other hazard types in several ways. First, unlike earthquakes, floods or tsunamis that occur along generally well-defined fault lines, river valleys or coastlines, drought can occur anywhere (with the exception of desert regions where it does not have meaning) (Goddard et al. 2003). Secondly, drought develops slowly, resulting from a prolonged period 
(from months to years) of water supply conditions that are below the average, or expected value, at a particular location (Dracup et al. 1980).

The immediate consequences of short-term droughts (i.e. a few weeks duration) are, for example, a fall in crop production, poor pasture growth and a decline in fodder supplies from crop residues, whereas prolonged water shortages (e.g. of several months or years duration) may, among others, lead to a reduction on hydro-electrical production and an increase of forest fire occurrences (Mishra and Singh 2009). Because of their long-lasting socioeconomic impacts, droughts are by far considered the most damaging of all natural disasters (Sivakumar et al. 2014). Over the United States, droughts cause \$6-8 billion per year damages on average, but as much as 22 events between 1980 and 2014 resulted in over $\$ 200$ billion costs (NCDC 2015). Current estimates by the European Commission (CEC 2007) indicate that the damages of droughts in Europe over the last 30 years are at least $€ 100$ billion. On top of that, the European Environmental Agency (EEA 2010) reported that the annual average economic impact from droughts doubled between 1976-1990 and 1991-2006, rising to $€ 6.2$ billion per year in the most recent period. In India a drought has been reported at least once in every 3 years in the last five decades (Mishra et al. 2009; UNISDR 2009a). Moreover, the country has suffered a financial loss of about $\$ 149$ billion and 350 million people got affected due to droughts in the past 10 years (Gupta et al. 2011).

In order to reduce the global threat of drought, an increasing number of international initiatives, such as the "Hyogo Framework for Action 2005-2015: building resilience of Nations and Communities to Disaster" (UNISDR 2009a, b) and the "High-level Meeting on National Drought Policy" (WMO 2013), have begun to encourage all the governments around the world to move towards a droughtresilient society. Although providing a safety net for those people or sectors most vulnerable to drought is always a high priority, the challenge now is to do it in a manner that engenders cooperation and coordination between different levels of governance in order to reinforce the tenets of proactive drought risk reduction strategies (Kampragou et al. 2011; Sivakumar et al. 2014; Wilhite et al. 2014). This new paradigm emphasizes greater understanding of the natural features of drought, amount of exposed elements and the factors that influence environmental, social and economic vulnerability. In this context, progress on global drought risk management is particularly important (Carrão et al. 2016).

Definitions of risk are commonly probabilistic in nature, referring to the potential impacts from a particular hazard in a future time period (Blaikie et al. 1994; Brooks et al. 2005). Drought risk is the probability of harmful consequences or likelihood of losses resulting from interactions between drought hazard (i.e. the possible future occurrence of drought events), drought exposure (i.e. the total population, its livelihoods and assets in an area in which drought events may occur), and drought vulnerability (i.e. the propensity of exposed elements to suffer adverse effects when impacted by a drought event) (Cardona et al. 2012). Expressed in another way, risk is determined not only by the physical intensity of the natural hazard and the amount of exposed entities, but also by the vulnerability of a society at a given moment in time. Vulnerability depends critically on the economic, social, and infrastructural characteristics of the locale or region and is dynamic in response to changes in the hazard and exposure (Wilhite et al. 2007).

Although there are three determinants of drought risk, any wise management of land and the environment, as well as improved preparedness to severe drought events, depend primarily on estimations of drought hazard magnitude and its distribution for the future (Dao and Peduzzi 2003; Hayes et al. 2004; Peduzzi et al. 2009; Cardona et al. 2012). Indeed, an assessment of simulated $d H$ conditions is recommended before any drought management plan is implemented and periodically revised thereafter (Wilhite et al. 2014). For example, several of the regions that have experienced recent droughts are important agricultural areas [e.g. Central Europe, parts of the US or India; see Ramankutty et al. (2008)], on which global food production may critically depend in the future (Foley et al. 2011). If $d H$ is confirmed to increase for these regions, then mitigation plans must be revised and updated to keep them productive and responsive to the needs of the citizens. Similarly, future drought in the Amazon region has been highlighted as a possible tipping element of the climate system (Lenton et al. 2008), involving potential large feedback to the global carbon cycle (Phillips et al. 2009; Lewis et al. 2011). Evaluating the uncertainty and likely range of $d H$ projections over that region is of key importance to raise awareness for long-term water supply issues that are not taken into account by governance for contemporary "non-drought" regions (Orlowsky and Seneviratne 2013). If regional $d H$ changes, then adequate prevention measures and adaptation strategies must be adopted by governments today to manage drought risk tomorrow, and mitigate the impacts of climate change on human populations and the environment.

In this study, we concentrate on the assessment of climate change effects on global patterns of drought hazard $(\mathrm{dH})$ around the middle and end of the twenty-first century. We aim at providing a benchmark for the development and implementation of pre-impact governmental programs that are intended to reduce future drought risk, and to complement recent studies on increasing drought conditions under global warming in observations and models e.g. (Dai 2013; Orlowsky and Seneviratne 2013; Penalba and Rivera 2013). While previous studies have focused on raw models at 
lower resolution, here we performed an analysis from five high resolution bias-corrected climate models participating to the Coupled Model Intercomparison Project Phase 5 (CMIP5; Taylor et al. 2012), as provided by the Inter-Sectoral Impact Model Intercomparison Project (ISI-MIP; Warszawski et al. 2014). To achieve our goal, we analyzed the global patterns of $d H$ for contemporary climate and their projected changes over the twenty-first century by means of the Weighted Anomaly of Standardized Precipitation (WASP) index (Lyon and Barnston 2005) The WASP-index has the advantage over the Standardized Precipitation Index (SPI) and the Palmer Drought Severity Index (PDSI) used in previous studies e.g. (Dai 2013; Orlowsky and Seneviratne 2013; Penalba and Rivera 2013) because it takes into account the dry and wet season(s) along the hydrological cycle, and calibrates the severity of drought events that occur at different times in the year. Moreover, and to the best of our knowledge, this is the first study in the literature that considers together the frequency and severity of drought events to compute $d H$. By focusing on $d H$ after identifying specific drought events, and not on projections of intensity for fixed timescales (e.g. months, seasons or years), we avoid splitting and smoothing the magnitude of extreme drought cases that spread over several fixed time periods.

This paper is organized as follows. Section 2 describes the methods and data used in this study. In Sect. 3, we perform an analysis of contemporary drought from observations and climate models, followed by a discussion about future changes in $d H$ and expected impacts. We conclude the paper with a summary of main achievements and their implications on Sect. 4.

\section{Datasets and statistical methods}

\subsection{Drought hazard estimation: the Weighted Anomaly of Standardized Precipitation (WASP) index}

Hazard refers to the natural or human induced events that potentially damage different places singly or in combination (Blaikie et al. 1994) In technical settings, hazards are described quantitatively by the probability that an event of a certain magnitude will occur at a certain place and time, as determined from historical data or scientific analysis (Reed 1997; UNISDR 2009b) Since precipitation is a proxy indicator of the water available to the coupled human-environment system (Svoboda et al. 2012) then the frequency of abnormal precipitation deficits at some level of intensity can be used to represent drought hazard for drought-prone nations and regions, as similar as proposed by Shahid and Behrawan (2008), He et al. (2012), Shiau and Hsiao (2012), and Kim et al. (2015).
The most widely known index of drought intensity is the Standardized Precipitation Index (SPI) proposed by McKee et al. (1993). The SPI is based on precipitation data alone and is a normalized measure relative to the expected precipitation accumulated at a specific time and location. Since its values are climatologically consistent across locations and accumulation periods, the SPI has been widely applied in the operational setting, namely in the United States (Svoboda et al. 2002) and Europe (Sepulcre-Canto et al. 2012), to cite but a few. Although the SPI provides a consistent classification for comparing precipitation deficits for multiple timescales of accumulation across space and time, it does not take into account the annual precipitation variability in estimating drought intensity. Therefore, intensity values computed from the cumulative sum of normalized precipitation deficits during a dry season can be as extreme as during a rainy season.

Since the timing of consecutive precipitation deficits relative to the local hydrologic cycle has more impact on the natural ecosystem and human activities than the seasonal or annual precipitation totals (Sharma 1996; Usman and Reason 2004; Lyon et al. 2012), then the contribution of months from rainy and dry periods to drought intensity should be proportional to the "weight" of monthly precipitation to the respective annual cycle (Byun and Wilhite 1999; Keyantash and Dracup 2002; Kallis 2008). For example, for crop cultivation, the consistency with which minimally required precipitation is received is more important than the total received over time (Sharma 1996; Usman and Reason 2004). A lack of water is more critical in the main season of occurrence, i.e. during the start of the rainy season and in the principal growth stages of rain-fed crops (Smakhtin and Schipper 2008). Therefore, the estimation of drought intensity without accounting for precipitation seasonality may mislead or delay mitigation actions, and result in significant impacts on people, the economy and the environment (Kampragou et al. 2011).

To enable for the effects of pronounced precipitation seasonality in the estimation of drought intensity, in this study we compute the magnitude of precipitation deficits by means of the Weighted Anomaly of Standardized Precipitation (WASP) index (Lyon and Barnston 2005). The reasons for selecting the WASP-index are threefold: (1) it is standardized in time and space, as similar as for the SPI; (2) allows to damp large standardized anomalies that result from small precipitation amounts occurring near the beginning or end of dry seasons; and (3) emphasizes anomalies during the core of rainy seasons (Andrade and Belo-Pereira 2015). The WASPindex is computed for each drought event $j$ by summing the weighted standardized monthly precipitation deficits, as follows (Lyon and Barnston 2005):

$W A S P_{j}=\sum_{P_{m, n}<\tau_{m}}^{P_{m, n} \geq \tau_{m}}\left(\frac{P_{m, n}-\tau_{m}}{\tau_{m}}\right) \frac{\tau_{m}}{\tau_{A}}$, 
where $P_{m, n}$ is the total precipitation for month $m=1, \ldots, 12$, and year $n ; \tau_{m}$ defines the monthly threshold of meteorological drought onset; and $\tau_{A}=\sum_{m=1}^{12} \tau_{m}$ is the maximum annual precipitation deficit due to drought conditions. A drought event $j$ starts when $P_{m, n}<\tau_{m}$, and ends when $P_{m, n} \geq \tau_{m}$. $\tau_{m}$ is computed from a time-series of precipitation totals, $P_{m, 1}, \ldots, P_{m, N}$, collected for month $m$ over a reference period of $N$ years (we focus on the period 1971-2000). The thresholds of drought onset are derived by means of the "Fisher-Jenks" classification algorithm, which estimates the precipitation totals that optimize the partition of the time-series into "drought" and "nondrought" months along the reference period $N$, as described in Carrão et al. (2014).

In this study, drought hazard $(d H)$ for grid point $i$ and 30-year period $t$ (1971-2000, 2021-2050, and 2071-2099) is estimated as the probability of exceeding the median of the WASP-index values computed for all grid points across the globe in the reference period of $N$ years:

$d H_{i, t}=1-\operatorname{Pr}\left\{W A S P_{i, t} \leq \operatorname{med}\left(W A S P_{g, N}\right)\right\}$,

where $W A S P_{i, t}$ represents the sorted set of WASP-index values for all drought events $j$ occurring at grid point $i$ in the 30-year period $t$, and med (WASP ${ }_{g, N}$ ) denotes the 50th percentile of the WASP-index values computed for all grid points across the globe in the reference period $N$.

\subsection{Climate model simulations}

To estimate potential $d H$ changes in the future, we use high-resolution climate model simulations derived from state-of-the-art general circulation models (GCMs) collected through the Coupled Model Intercomparison Project Phase 5 (CMIP5; Taylor et al. 2012 and exploited in the framework of ISI-MIP, the first Inter-Sectoral Impact Model Intercomparison Project (Warszawski et al. 2014). ISI-MIP is designed to provide a consistent set of global impact projections in the agriculture, water, biome, health, and infrastructure sectors at different levels of global warming (Hempel et al. 2014). To provide the associated climate information for ISI-MIP, five CMIP5 simulations were selected, namely: HadGEM2-ES, IPSL-CM5A-LR, MIROC-ESM-CHEM, GFDL-ESM2M, and NorESM1-M
(Table 1). These five models were selected based on the availability of data for the required variables covering the period from 1 January 1950 to 31 December 2099, i.e. historical and all Representative Concentration Pathway (RCP) scenarios in the CMIP5 archive at the beginning of the ISI-MIP project (Hempel et al. 2014).

The CMIP5 model simulations selected for the ISI-MIP climate dataset were bi-linearly interpolated in space to a $0.5^{\circ}$ latitude/longitude spatial resolution grid, as described by (Hempel et al. 2014). Moreover, the time-series were linearly interpolated to the standard Gregorian calendar (365 days per year plus leap days) wherever necessary. The data were also bias-corrected to ensure long-term statistical agreement with the observation-based GPCCv4WATCH forcing data (Weedon et al. 2011) over the period 1960-1999. The need for bias-correcting model projections is well known, as impact models may be significantly dependent on the occurrence and frequency of extreme events (Christensen et al. 2008). Precipitation, and especially convective precipitation, is strongly dependent on details of climate models parametrization, and the use of a bias-corrected ensemble gives more robust results in the projection of climate change (Russo et al. 2013). For instance, Rojas et al. (2011) showed that bias-corrected data significantly improve the simulation of river flood for the present climate. Bias-correction of ISI-MIP daily series of precipitation was performed by Hempel et al. (2014), following the method described in Piani et al. (2010). This approach was previously used by Dosio and Paruolo (2011) and Dosio et al. (2012) to perform the bias-correction of ENSEMBLES daily series of temperature and precipitation. Dosio and Paruolo (2011) showed that bias-correction improved the present climate mean statistics and the timedependent properties, such as the number of consecutive dry days and the cumulative amount of rainfall for consecutive heavy precipitation days.

In this study, we concentrate in three emissions scenarios, termed Representative Concentration Pathways (RCP) by the Intergovernmental Panel on Climate Change (IPCC) and explained in detail in Moss et al. (2010). All scenarios specify radiative forcing relative to pre-industrial conditions, with the 20th century increasing from 1.04 to $2.08 \mathrm{~W} / \mathrm{m}^{2}$ during the period 1971-2005. The emissions
Table 1 CMIP5 climate model simulations used in this study

\begin{tabular}{lll}
\hline Model name & Modeling group & Country \\
\hline HadGEM2-ES & UK Met Office Hadley Centre & UK \\
IPSL-CM5A-LR & Institute Pierre Simon Laplace & France \\
MIROC-ESM-CHEM & University of Tokyo, National Institute for Environmental Studies, & Japan \\
& $\quad$ and Japan Agency for Marine-Earth Science and Technology & \\
GFDL-ESM2M & Geophysical Fluid Dynamics Laboratory (GFDL) & USA \\
NorESM1-M & Norwegian Climate Centre & Norway \\
\hline
\end{tabular}


scenarios deviate at 2005 and are named based on their radiative forcing values in 2100 . The RCP8.5 scenario is the most severe, with greenhouse gases continuing to increase through the next century, resulting in radiative forcings of $8.5 \mathrm{~W} / \mathrm{m}^{2}, \mathrm{CO}_{2}$ concentrations of $1370 \mathrm{pppm}$ and a temperature anomaly of $4.9^{\circ} \mathrm{C}$ by 2100 . The RCP4.5 scenario represents a medium future scenario, where greenhouse gases and therefore radiation stabilize by the end of the century with an overshoot at $4.5 \mathrm{~W} / \mathrm{m}^{2}, 650 \mathrm{ppm} \mathrm{CO}_{2}$, and a temperature anomaly of $2.4{ }^{\circ} \mathrm{C}$. The least severe future scenario is the RCP2.6, which includes a mid-century peak at $3 \mathrm{~W} / \mathrm{m}^{2}$ before declining to $2.6 \mathrm{~W} / \mathrm{m}^{2}, 490 \mathrm{ppm}$ $\mathrm{CO}_{2}$, and a temperature anomaly of $1.5^{\circ} \mathrm{C}$.

Calculation of the WASP-index (Sect. 2.1) for contemporary and future climates relies on daily precipitation $(\mathrm{kg}$ $\mathrm{m}^{-2} \mathrm{~s}^{-1}$ ) accumulated at monthly resolution.

\subsection{Statistical methods}

In this study, projections of drought hazard $(d H)$, as well as the magnitude of their changes in a warming future, are estimated by means of the WASP-index values (Sect. 2.1, Eq. 1) calculated for all consecutive monthly precipitation deficits within three 30-year periods $t$ : (1) 1971-2000, (2) 2021-2050, and (3) 2071-2099, which we denote as contemporary climate, near future, and future, respectively. Note that previous studies addressed both the frequency and intensity of projected drought changes e.g. (Sheffield and Wood 2008; Orlowsky and Seneviratne 2013; Spinoni et al. 2015a). Here we focus on $d H$ only, which values summarize both statistics: a projected positive change of $d H$ results in a larger proportion of severe drought events and an increase of their median magnitude. Projected changes in $d H$ at each grid point are defined with respect to a reference period $N$, in our case 1971-2000 (present climate). In transient climate simulations, when the greenhouse forcing gradually changes, the assumption of stationarity is not necessarily valid, since, over a period of 50 years or more, the climate change signal can be significant (Nikulin et al. 2011). In our case, however, since we use only 30-year time-series of model-simulated monthly precipitation totals, the climate change signal is expected to be small. Hence, with good approximation, we can treat 30 years as stationary (Russo and Sterl 2012).

\subsubsection{Ensemble consistency}

The climate models that we are using in this study are tools that have been developed to understand and to represent specific features of the real climate system of the Earth. In order to be useful for this purpose, it is necessary to evaluate the capability of such models to realistically represent these features (Notz 2015; Pascale et al. 2015). Therefore, before entering into the analysis of future changes in $d H$, we first evaluate its representation in the climate models for the reference period 1971-2000. Model evaluation is commonly based on the direct comparison between simulation results and measurements of individual observables e.g. (Dai 2013; Russo et al. 2013; Gulizia and Camilloni 2015). Here we compare the simulated $d H$ from individual models, as well as the mean (CMIP5-EMean) and median (CMIP5-EMed) of their ensemble, to the $d H$ computed with monthly precipitation totals from the GPCCv4-WATCH forcing data. Differences at each grid point were quantified by means of the Pearson product-moment correlation coefficient, $r$, a widely used measure of the degree of linear dependence between two datasets (Duveiller et al. 2016). The single model or ensemble statistic (mean or median) with the highest agreement is selected for projecting future changes in the geographic patterns and magnitudes of $d H$ globally. It should be noted that although the GPCCv4WATCH forcing data was used to perform the bias correction of individual monthly precipitation totals for the five models under contemporary climate, here we are looking at the correlation between a new random variable (i.e. $d H$ ) that is independent from individual monthly precipitation totals and has a different probability distribution.

As some climate models project a significant wetter climate, while others project a drier one, there is an uncertainty in future changes that may have a large impact when the whole ensemble of data is used for deriving joint statistics, i.e. CMIP5-EMean and CMIP5-EMed (Russo et al. 2013). To give the same weight to the five models, we compute CMIP5-EMed as the median of the expected drought hazard for each model, as emphasized by, e.g. Reichler and Kim (2008), Pierce et al. (2009), Feng and Fu (2013), Russo et al. (2013), and Huang et al. (2015). To perform a statistical sound comparison, we compute CMIP5-EMean as the average of expected drought hazard for each model.

We also investigate the regional consistency between simulations and observations for contemporary climate under the paradigm of a statistically indistinguishable ensemble. Despite the fact that the link between models' performance for contemporary climate and the performance for a future climate is often not clear, the assessment of the ensemble consistency provides a necessary proxy for the evaluation of the ensemble accuracy in the future under large uncertainties and due to the lack of an observed climate (Bothe et al. 2013; Notz 2015; Pascale et al. 2015). In this type of analysis, the null hypothesis is that observations and simulations are statistically indistinguishable and, therefore, are exchangeable with each other (Wilks 2005). The concept of indistinguishability or exchangeability bases on the assumption that the observed climate system is sampled from the ensemble of climate models (Bothe et al. 2013). To assess whether the ensemble of simulated $d H$ can 
be considered to be consistent with the observed $d H$, we use a robust and non-parametric location test based on the median absolute deviation (MAD) of simulated $d H$, which is computed as (Huber et al. 1981):

$$
M A D=b \text { med }\left|d H_{\bmod (k)}-C M I P 5-E M e d\right|,
$$

where $d H_{\bmod (k)}$ is the expected $d H$ from climate model $k$, and $b$ is a constant needed to make the estimator consistent for the distribution of interest (Rousseeuw and Croux 1993). We empirically estimate $b=1 / Q(0.75)$, as suggested by Leys et al. (2013), where $Q$ stands for quantile. The consistence of the ensemble is assessed by testing the null hypothesis that the median $d H$ across all models is the same as the observed $d H$ under contemporary climate. As proposed by, e.g. Iglewicz and Hoaglin (1993), Rousseeuw and Croux (1993), and Leys et al. (2013), the null hypothesis can be rejected for test values $>2.5$, which are computed as follows:

$$
\frac{\left|d H_{o b s}-C M I P 5-E M e d\right|}{M A D},
$$

where $d H_{o b s}$ is the observed $d H$ computed from the GPCCv4-WATCH forcing data. For rejected points, we conclude that the climate ensemble is not consistent with contemporary climate and exclude these grid points from the analysis of changes in future $d H$.

\subsubsection{Robustness and significance of climate projections}

To assess whether $d H$ in a future time period $t$ is distinct from that in the reference period $N$, we used a method adapted from previous works, namely Tebaldi et al. (2011), Knutti and Sedlek (2013) and Jacob et al. (2014). This method identifies regions with relatively robust and significant climate changes from an ensemble of model simulations, and can be applied to projections on regular model grids or to data aggregated onto larger regions. As pointed out by Tebaldi et al. (2011), there is a fundamental difference between lack of signal (i.e. lack of detection of a significant response to anthropogenic forcing) versus lack of agreement in the signal (i.e. when different models produce changes of opposite sign). We use two statistical tests to analyze the significance and robustness of future $d H$ changes given by the ensemble of climate projections. Only regions that pass both tests are identified as regions with robust and significant $d H$ changes.

The first test regards the agreement of individual simulations in terms of the direction of the changes, i.e robustness. We use the consensus between the five models to measure the uncertainties associated with natural variations and model errors, and defined robust changes in grid points where more than $80 \%$ of the models agree (i.e. 4 out of 5), as similar as Jacob et al. (2014) and Alfieri et al. (2015). The idea is that if multiple models, based on different but plausible assumptions, simplifications and parameterizations, agree on a result, we have higher confidence than if the result is based on a single model, or if models disagree on the result (Knutti and Sedlek 2013).

In the second test, the changes are assessed by means of the $p$ values of the Mann-Whitney-Wilcoxon test (Storch and Zwiers 2003; Wilks 2005; Swain and Hayhoe 2015) for the ensemble of simulations. This statistical test, which is non-parametric and has the advantage of making no assumptions about the distribution of the data, is used to determine whether CMIP5-EMean computed for the reference period $N\left(d H_{N}\right)$ and future period $t$ $\left(d H_{t}\right)$ are significantly different, precisely, whether or not are drawn from the same distribution at a chosen level of significance. As similar as for Sheffield and Wood (2008) and Swain and Hayhoe (2015), we only quantify the magnitude of changes for those grid points where the null hypothesis that $d H_{N}$ and $d H_{t}$ are drawn from the same population is rejected at the $5 \%$ significance level.

On account of the fact that dealing with drought concepts in contemporary hyperarid and cold regions is physically meaningless (Lyon and Barnston 2005; Carrão et al. 2014; Spinoni et al. 2015b), we used the global aridity index dataset from Spinoni et al. (2015b) to exclude these areas from drought change analysis, as similar as Russo and Sterl (2012) and Carrão et al. (2016). Moreover, since GCMs have difficulty in simulating very dry conditions (Sterl et al. 2008), the exclusion of the hyperarid regions from our analysis is also important because future precipitation changes are difficult to interpret there. As many authors have discussed, e.g. Giannini (2010), Biasutti and Giannini (2006), Cook and Vizy (2006), and Douville et al. (2006) to cite but a few, projections of precipitation changes for the twenty-first century are very uncertain in those regions, with equal numbers of models predicting a significantly wetter or drier future, or no significant change with respect to present conditions at all.

\section{Results and discussion}

First, we determine whether climate models are capable of reproducing contemporary drought hazard $(d H)$ at the global level by comparing the hazard computed from single models, and their ensemble, to observationbased data. Afterwards, we look into the identification and quantification of changes in $d H$ at the near future and future. 


\subsection{Analysis of contemporary $d H$ from observations and climate models}

In Fig. 2, we present the global maps of $d H$ under contemporary climate, as computed with the monthly precipitation totals from GPCCv4-WATCH forcing data (i.e. $d H_{o b s}$ ), and the ensemble mean $d H$ from individual CMIP5 models (i.e. CMIP5-EMean). Looking at Fig. 2(a), it is noticeable a match between the geographic distribution of global $d H_{o b s}$ and the wide range of global dry regions, as depicted by the global map of aridity computed by Spinoni et al. (2015b). Our experiments are consistent with previous results presented by Seager et al. (2007), Dai (2011), Spinoni et al. (2014), and Güneralp et al. (2015): $d H$ is generally high for semiarid areas, such as Northeastern and Southern South America, Northern, Southwestern and Horn of Africa, Central Asia, Australia, West US and the Iberian Peninsula; and low for tropical regions, such as the Amazon, Central Africa and Southern Asia. Let us also look in detail at the regional pattern of $d H_{o b s}$ for Latin America (LA). In 1936, the Semi-Arid Region of Northeast Brazil (SARNB, black polygon in Fig. 2a) was officially recognized by the federal government as having a common recurrence of drought episodes and it was delimited under the name of Drought Polygon to augment the governmental support to the resident populations living there (Brasil-MMA 2004; Brasil-MI/MMA/MCT 2005). The results shown in Fig. 2a confirm that the geographic distribution of $d H$ for Northeast Brazil is overall consistent with the geometric shape of the Drought Polygon (Brasil-MI/MMA/MCT 2005). These results seem to emphasize the validity of the WASP-index at estimating $d H$ and lend additional support to its use over the globe, for multiple geographic scales and different precipitation regimes. Moreover, it supports the use of the GPCCv4-WATCH for evaluating the consistency of the $d H$ simulations in contemporary climate.

In Table 2, we present the Pearson product-moment correlation coefficient, $r$, between the hazard computed with the GPCCv4-WATCH and the models for contemporary climate. The results suggest that the ensemble mean $d H$ (CMIP5-EMean) outperforms the respective median (CMIP5-EMed), as well as the hazard computed with individual simulations. Moreover, our outcomes confirm and strengthen the results of previous studies, such as Pierce et al. (2009), Feng and Fu (2013), and Huang et al. (2015), in that the mean of individual simulations correlates better to the climate variable being projected into the future. As the mean can filter uncertainty from inter-model variability, it is generally the best representation of the response to imposed anthropogenic forcing, and it is better than any individual member (Reichler and Kim 2008; Pierce et al. 2009; Feng and Fu 2013; Huang et al. 2015). Indeed, most of the observed patterns of $d H$ computed with the GPCCv4-WATCH are consistently simulated by the CMIP5-EMean computed from the average of individual CMIP5 models (Fig. 2b). The geographic distribution of $d H$ is matching for most of north America, Europe and the Mediterranean region, south Australia, central Africa, south and east Asia, and southwest of South America.

Notwithstanding the CMIP5-EMean shows the best global correlation with the $d H_{o b s}$, it is also very important to evaluate the consistency of the ensemble, i.e. if the $d H_{o b s}$ behaves like a random draw from the probability distribution describing the ensemble of climate models (Wilks 2005). In Fig. 3, we present the geographic distribution of the test statistic values assessing the ensemble consistency, as defined in Eq. (4). Overall, the results suggest that the CMIP5-EMean is less consistent with $d H_{o b s}$ for those regions placed in the subtropical subsidence zones around $10^{\circ}$ and $30^{\circ} \mathrm{N} / \mathrm{S}$, such as subtropical south Africa, north Australia, western India, Sub-Saharan Africa, and the region between middle-east and the Hindu Kush-Karakoram mountain ranges. It is noticeable a match between the geographic distribution of statistical disagreements among observed and simulated $d H$, and the arid regions with highly marked precipitation seasonality, as measured by the relative entropy indicator proposed by (Pascale et al. 2015). They found that the models participating to the CMIP5 project, systematically overestimate the distribution of monthly precipitation throughout the year in arid and semiarid regions with intermittent precipitation regimes-like the sub-Saharan Sahel—due to, in most cases, an excess of rainfall during the premonsoonal months. Interestingly, this pattern is not verified east of the Andes in South America. A plausible explanation is the southward flowing low-level jet (LLJ) that develops along the eastern Andean flanks and constantly transports moisture from the tropics to the subtropics (Campetella and Vera 2002; Soares and Marengo 2009; Insel et al. 2010). Nevertheless, to avoid contradictory analyses regarding the magnitude of future $d H$ for some of the so-called monsoon regions (Wang and Ding 2008), we add inconsistent grid points to the mask defined in Fig. 1 and do not account for changes at these regions.

In Fig. 4, we present a scatterplot of $d H_{o b s}$ and CMIP5EMean (as depicted, respectively in Fig. 2a, b). Plotted on the horizontal axis are the $d H_{o b s}$ values. The CMIP5EMean for corresponding grid points are plotted on the vertical axis: (a) all grid points; (b) after removing not consistent grid points identified in Fig. 3. The $r$ value between $d H_{o b s}$ and CMIP5-EMean is of 0.59 for Fig. 4a (Table 2) and of 0.75 for Fig. $4 \mathrm{~b}$. These results show that by removing the inconsistent grid points of intermittent precipitation regimes located in the subtropical subsidence zones from the analysis (orange cloud dressing the center right area in Fig. 4a), the CMIP5-EMean approximates the geographic pattern of contemporary global $d H$ conditions. Recently, 
Fig. 1 Hyperarid and cold regions not included in global drought change analysis

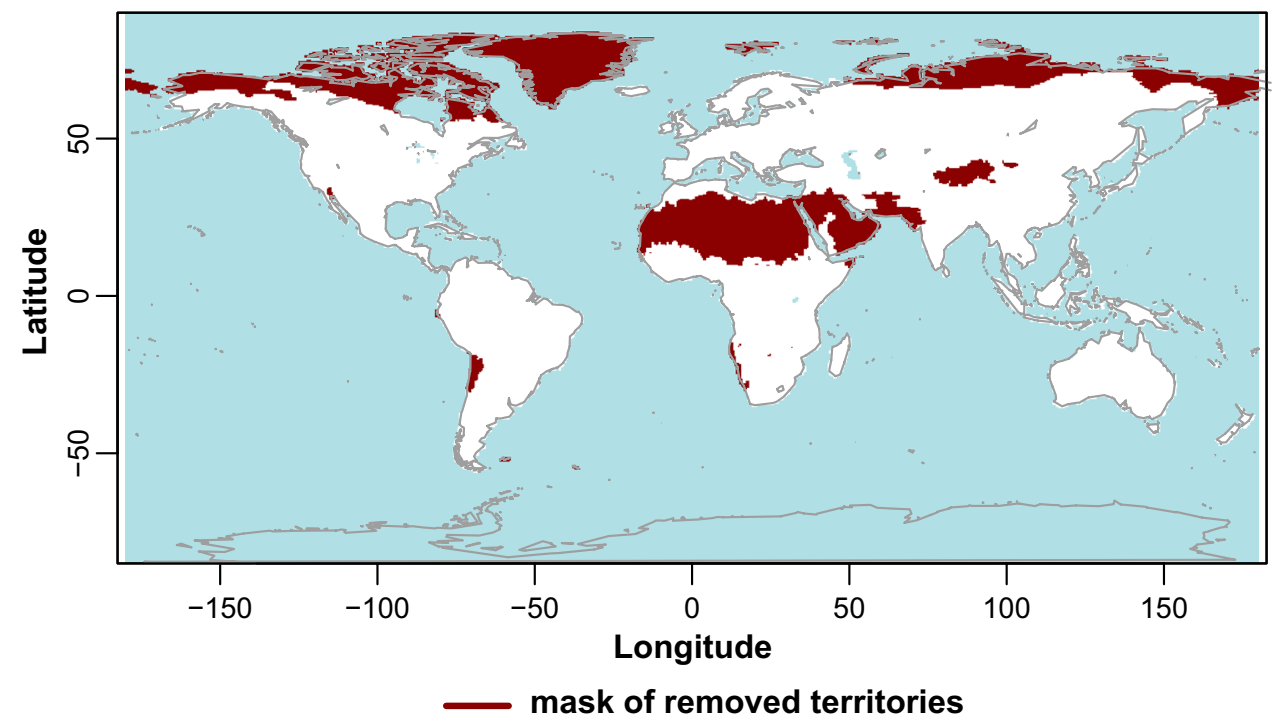

(a)

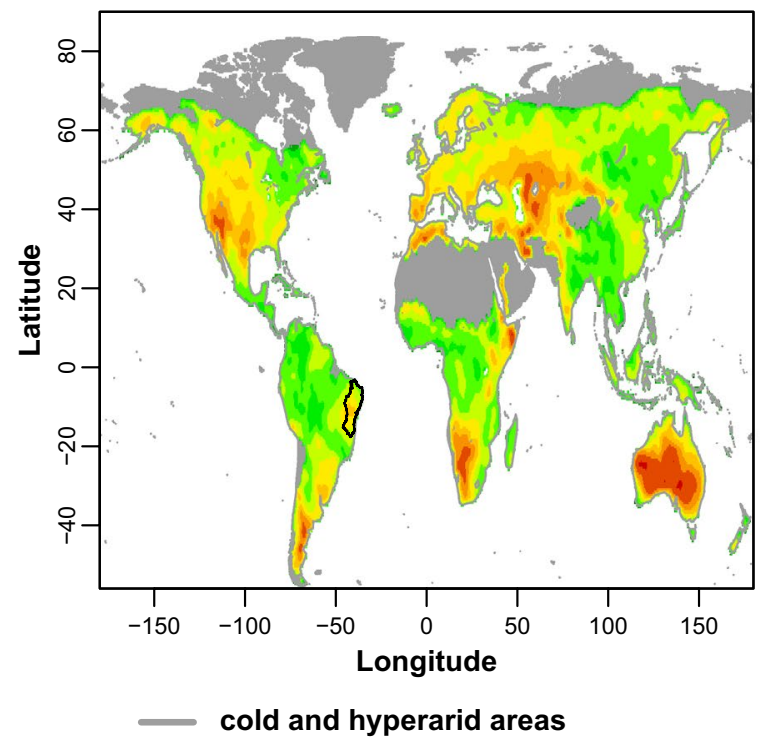

Fig. 2 Global maps of $d H$ for the period 1971-2000: a computed with monthly precipitation totals from GPCCv4-WATCH forcing data; b computed as the multi-model ensemble mean $d H$ (CMIP5- (b)

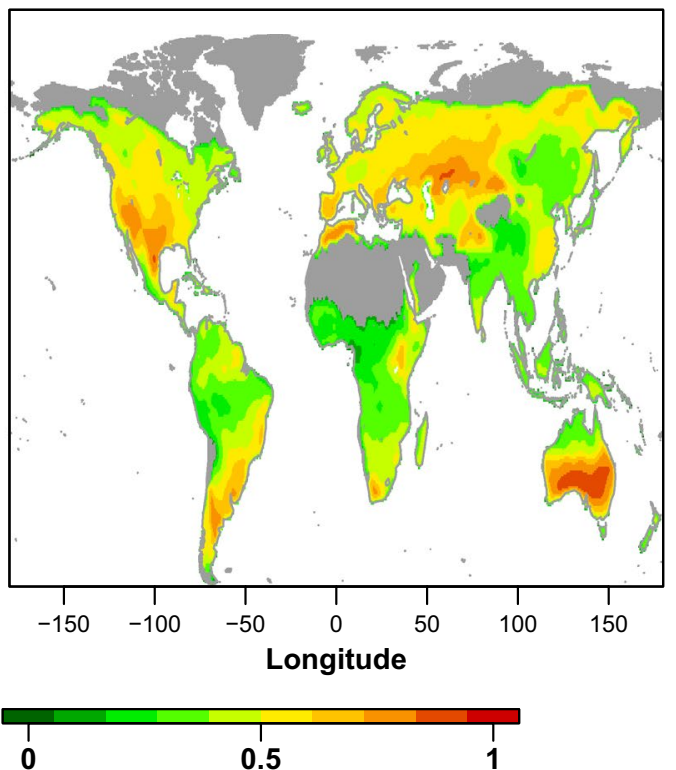

EMean). The Semi-Arid Region of Northeast Brazil (SARNB) is delimited in black (left panel)
Table 2 Pearson product-moment correlation coefficient $(r)$ between the $d H$ computed with monthly precipitation totals from GPCCv4WATCH forcing data for the period 1971-2000 and the $d H$ computed with monthly precipitation totals from CMIP5 models (ensemble median (CMIP5-EMed) and mean (CMIP5-EMean), and individual models) for the same time period

\begin{tabular}{llllllll}
\hline & CMIP5-EMed & CMIP5-EMean & HadGEM2-ES & IPSL-CM5A-LR & MIROC-ESM-CHEM & GFDL-ESM2M & NorESM1-M \\
\hline GPCCv4-WATCH & 0.58 & 0.59 & 0.47 & 0.56 & 0.51 & 0.50 & 0.51 \\
\hline
\end{tabular}


Fig. 3 Geographic agreement between CMIP5-EMean and $d H_{o b s}$. The hatched areas correspond to subtropical subsidence zones, as defined in Pascale et al. (2015)

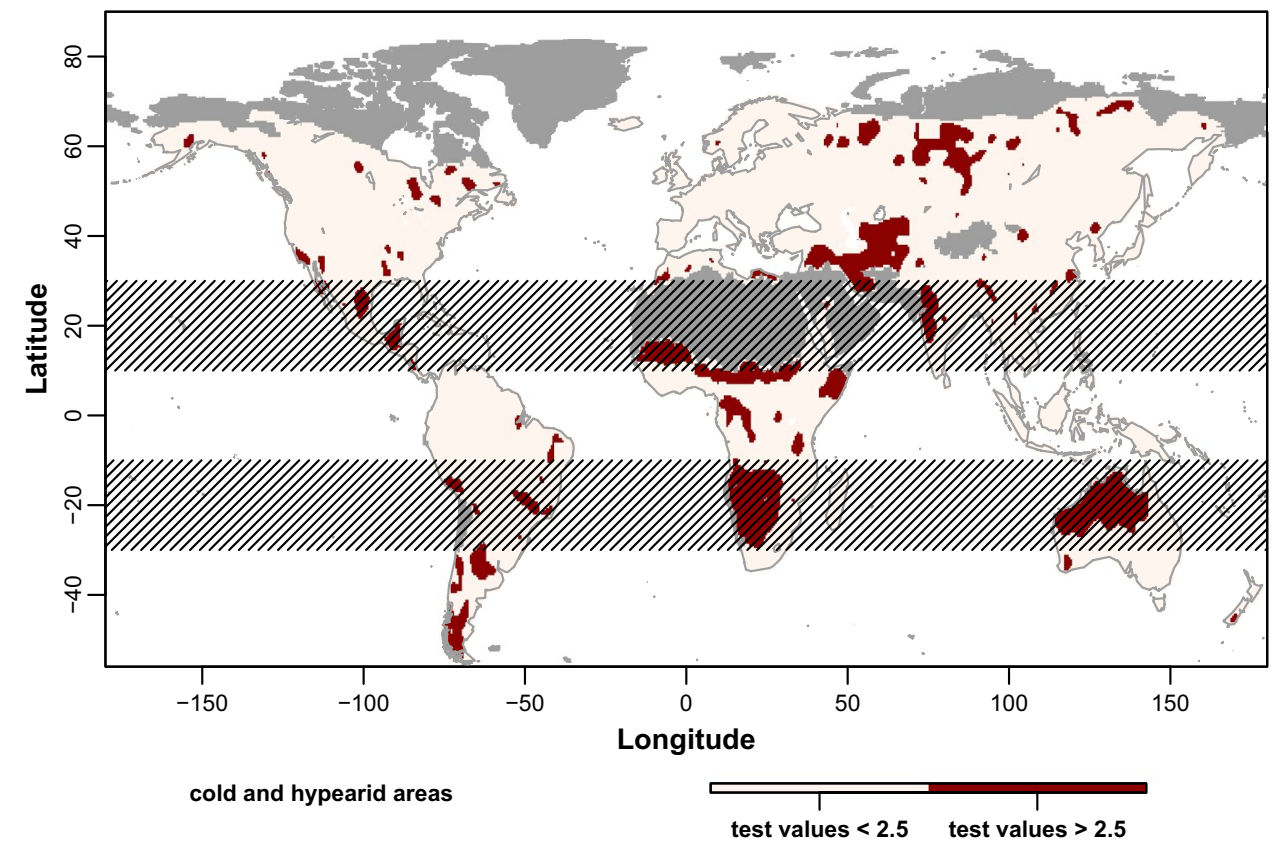

(a)

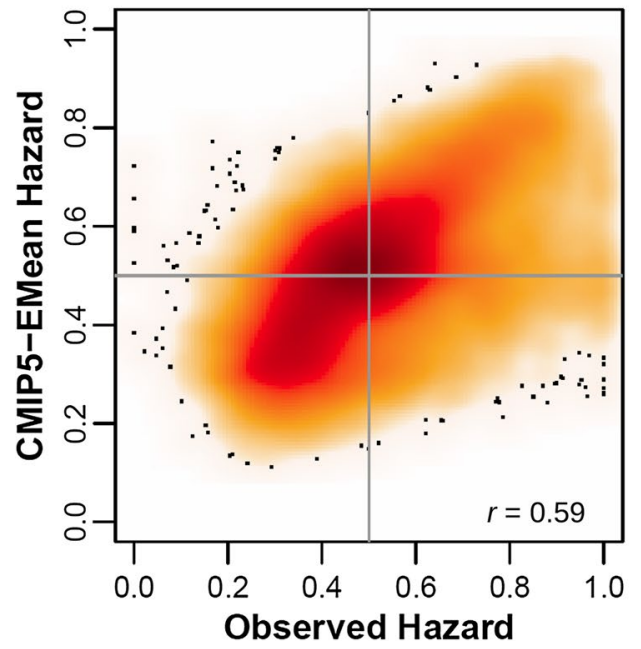

(b)

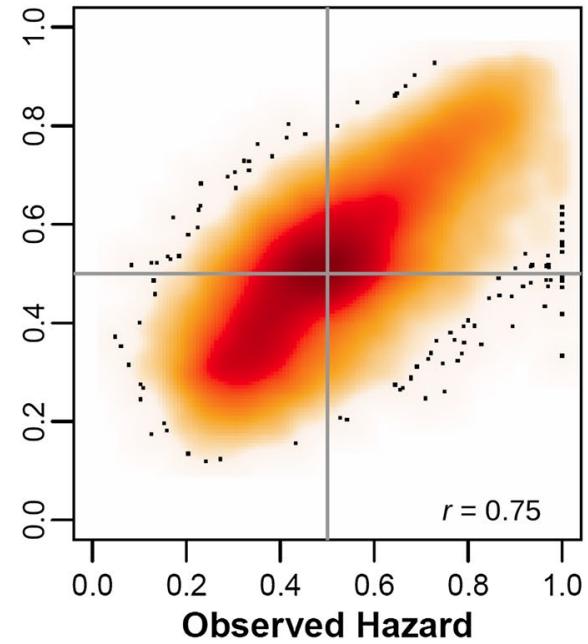

Observed Hazard
Fig. 4 Smoothed color density
representation of $d H_{\text {obs }}$ and CMIP5-EMean. a All grid points; $\mathbf{b}$ after removing not consistent grid points identified in Fig. 3 with values above 1 being indicative of an exacerbated disagreement between models. In our case, all grid points present small to medium $\mathrm{CVs}$, indicating a good agreement between the five climate models for the period 1971-2000. Nevertheless, and to complement the results presented in Fig. 3, we are of the opinion that future drought changes should also be evaluated prudently for central Africa, maritime Southeast Asia, northwest of South America, as the CVs are the highest for those regions. In fact, and given the high uncertainty in the simulations, it can be reasonably assumed that decisions related to the establishment or reinforcement of preparedness plans for adaptation and mitigation in those regions can be devious for stakeholders. This is increasingly relevant for those food-insecure 
Fig. 5 Geographic distribution of the coefficient of variation $(\mathrm{CV})$, calculated as the ratio between the standard deviation and the mean of the ensemble drought hazard

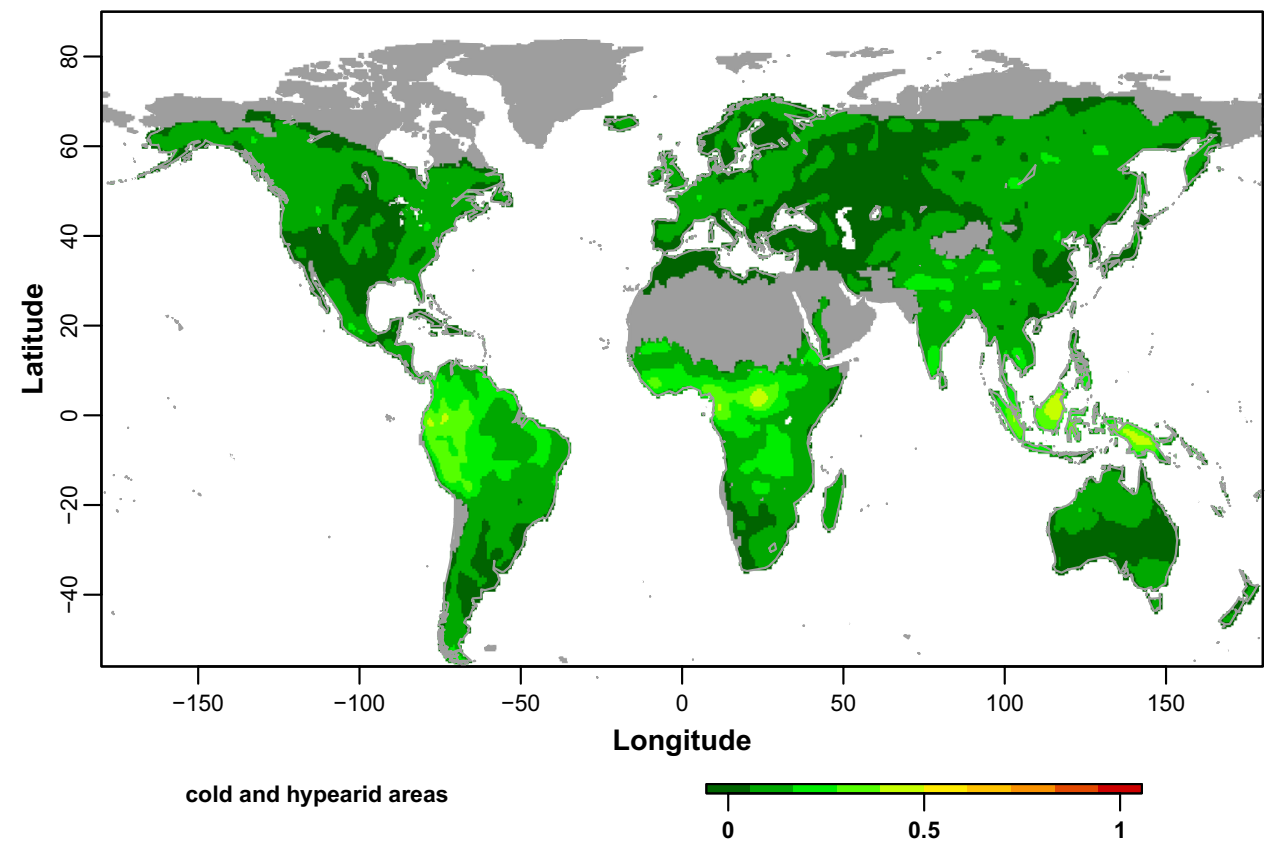

African regions with high dependence on subsistence agriculture and primary sector activities that have been subject to severe impacts in the 1980's: drought events combined with poor governance and poorly functioning market systems, oppressive policies, and intermittent or insufficient food aid, had historically lead to food insecurity, famine, human conflicts and widespread mortality there (Hulme 1996; Reed 1997; Below et al. 2007; Gráda 2007; Traore et al. 2014).

\subsection{Future changes in drought hazard}

Figures 6 and 7 show, respectively, near future (2021-2050) and future (2071-2099) percentage changes of $d H$, as measured by means of the CMIP5-EMean. The period 1971-2000 is used as the reference $(N)$ to measure future percentage changes of $d H$. The changes are calculated for three Representative Concentration Pathways (RCPs): 2.6, 4.5 and 8.5 , respectively at the top, middle and bottom of Figs. $6 \mathrm{a}$ and $7 \mathrm{a}$. In Figs. $6 \mathrm{~b}$ and $7 \mathrm{~b}$, regions where $d H$ changes are robust according to the first test are colored in light green, whereas regions that are robust and show significant changes at the chosen $95 \%$ confidence level are colored in dark green. Note that significant changes are always robust in our analysis. Non-robust and non-significant regions are colored in pink, whereas cold and hyperarid areas, as well as grid points of inconsistent $d H$ across climate models for contemporary climate (as defined in Fig. 3) are colored in grey.

In general, $d H$ increases globally between the twentieth century and both future time periods (Figs. 6a, 7a). More interestingly though, is the fact that the geographic patterns of increasing and decreasing $d H$ look very similar for middle and late twenty-first century, as well as for the three RCPs. In the one hand, the extend of positive $d H$ changes is projected to cover nearly all of the continental areas of North and South America, Europe, West and South Africa, East Asia and Australia. The projected positive changes in $d H$ are consistent with the CMIP3 drought analysis in Sheffield and Wood (2008), CMIP5 drought analysis in Prudhomme et al. (2014), and follow the tendencies of regional precipitation decreases projected with simulations from CMIP5 by Dai (2013), Feng et al. (2014), Knutti and Sedlek (2013), and Orlowsky and Seneviratne (2013). On the other hand, and as similar as for Feng et al. (2014) and Orlowsky and Seneviratne (2013), models agree that $d H$ will decrease in some drought hot spot regions of the last decades, such as Central Asia, South and Southeast Asian monsoon regions, and East Africa.

\subsubsection{Projections for the period 2021-2050}

Let us look in detail at the magnitude, robustness and significance of $d H$ changes at the near-future. Although decision makers are usually more interested in the 10-30 year time horizon (Pulwarty 2003), we did not find substantial differences between the magnitude of $d H$ changes for the three RCPs in the middle of the century: with a few exceptions, $d H$ is varying spatially by at most $\pm 25 \%$ (Fig. 6a), and the geographic consensus (more than 80\%) of the projected $d H$ among the five models is restricted to a few and sparse areas in central of South America, southeast US, the Iberian Peninsula, east China and south Australia (Fig. 6b). Drying scenarios are about as likely as reduced drought 
(a)
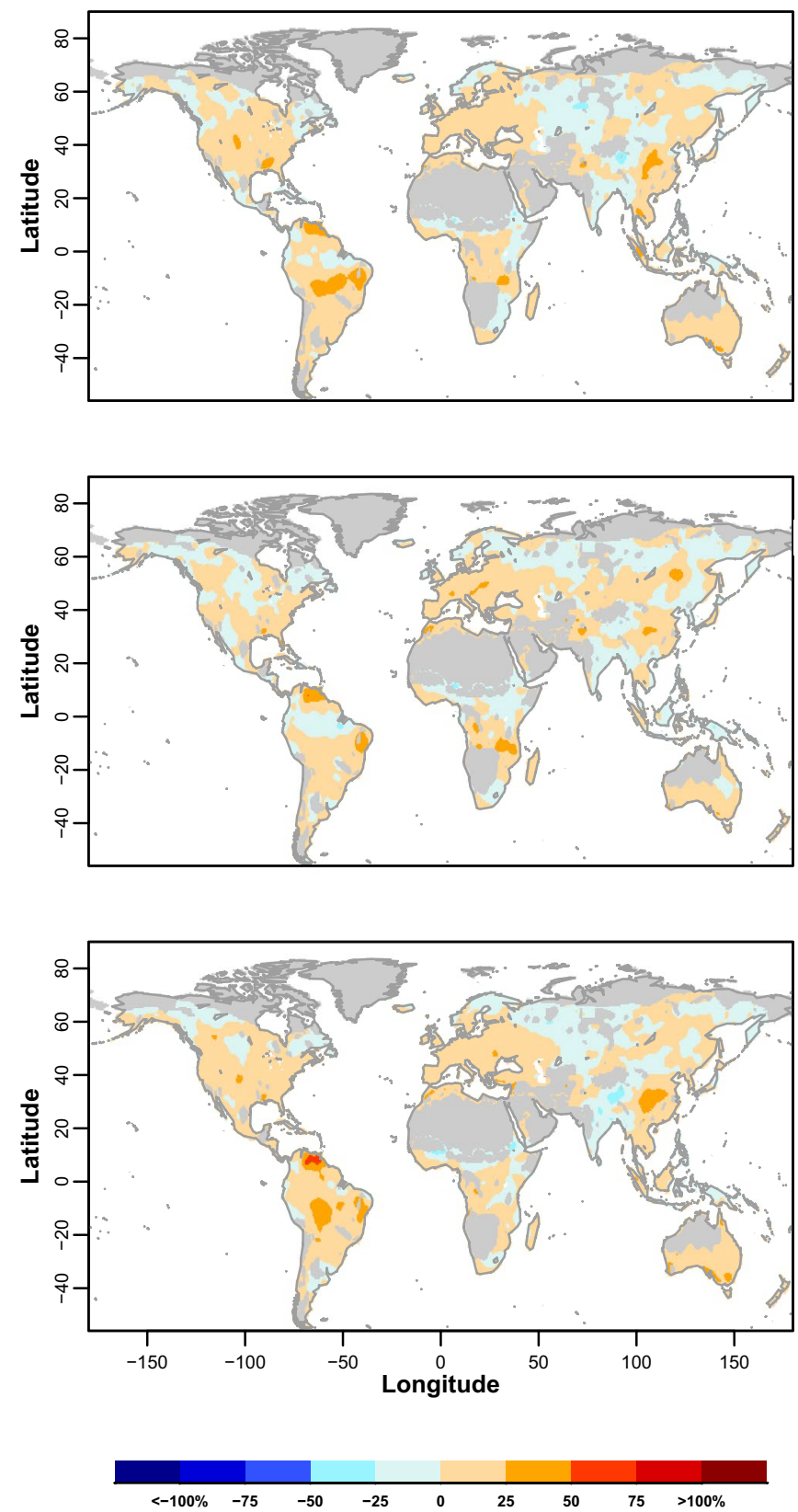

Fig. 6 a Percentage change in CMIP5-EMean between the reference period (1971-2000) and near future (2021-2050) under the RCP2.6 (top), RCP4.5 (middle) and RCP8.5 (bottom) scenarios. b Robust-

conditions in most regions and, not surprisingly, statistical significant changes, as defined by the Mann-Whitney-Wilcoxon test (see Sect. 2.3), are difficult to pinpoint around the world (Fig. 6b). Arguably, mild changes in $d H$ should not be mistaken for low drought risk in the near future, since projections for most regions are neither significant nor consensual, and still include the possibility of increasing magnitude, even in the cases where the average projections point towards wetter conditions. (b)
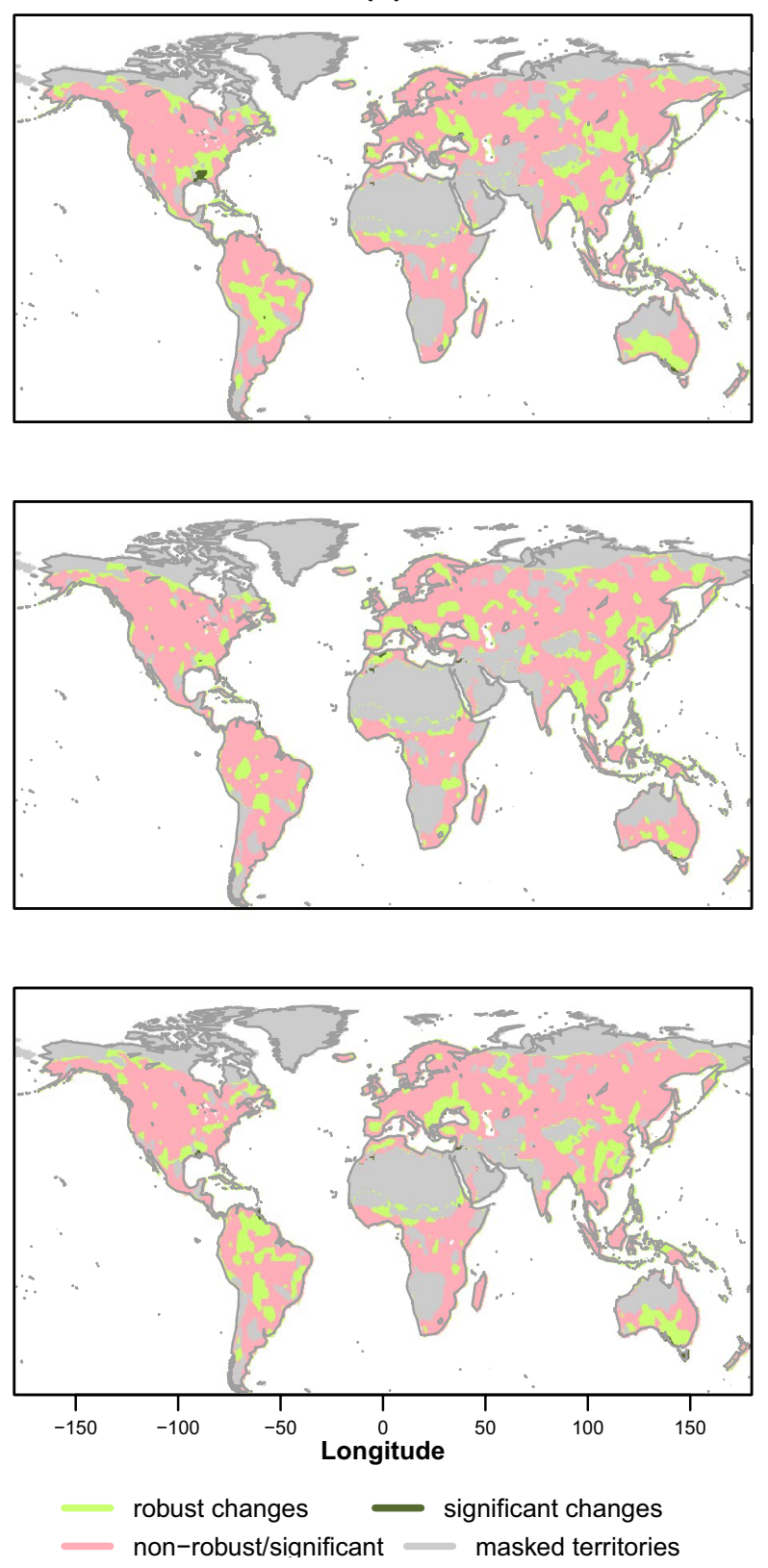

ness and significance of $d H$ changes under the RCP2.6 (top), RCP4.5 (middle) and RCP8.5 (bottom) scenarios; significant changes (dark green) are always robust

These results might leave stake-holders worrying about a near future that projects increasing $d H$ conditions over large regions, but lacking consensus among models, thus feeling paralyzed by the lack of actionable information to take decisions related to prevention and adaptation to future $d H$. Note, however, that these results do not contradict the patterns from previous studies and are not missing part of the phenomenon, but highlight the inherent ambiguity in decadal $d H$ predictions from 
(a)
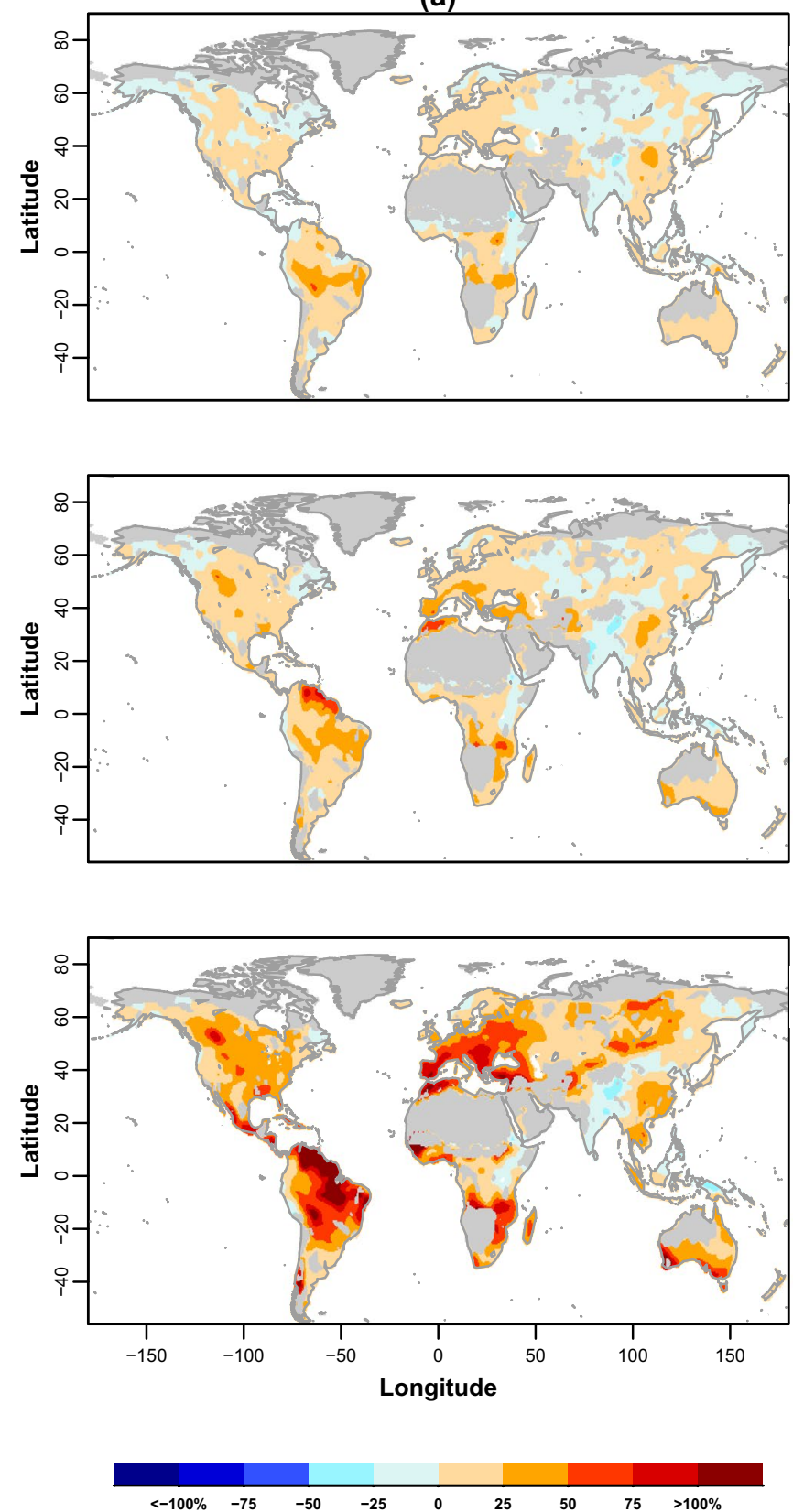

(b)
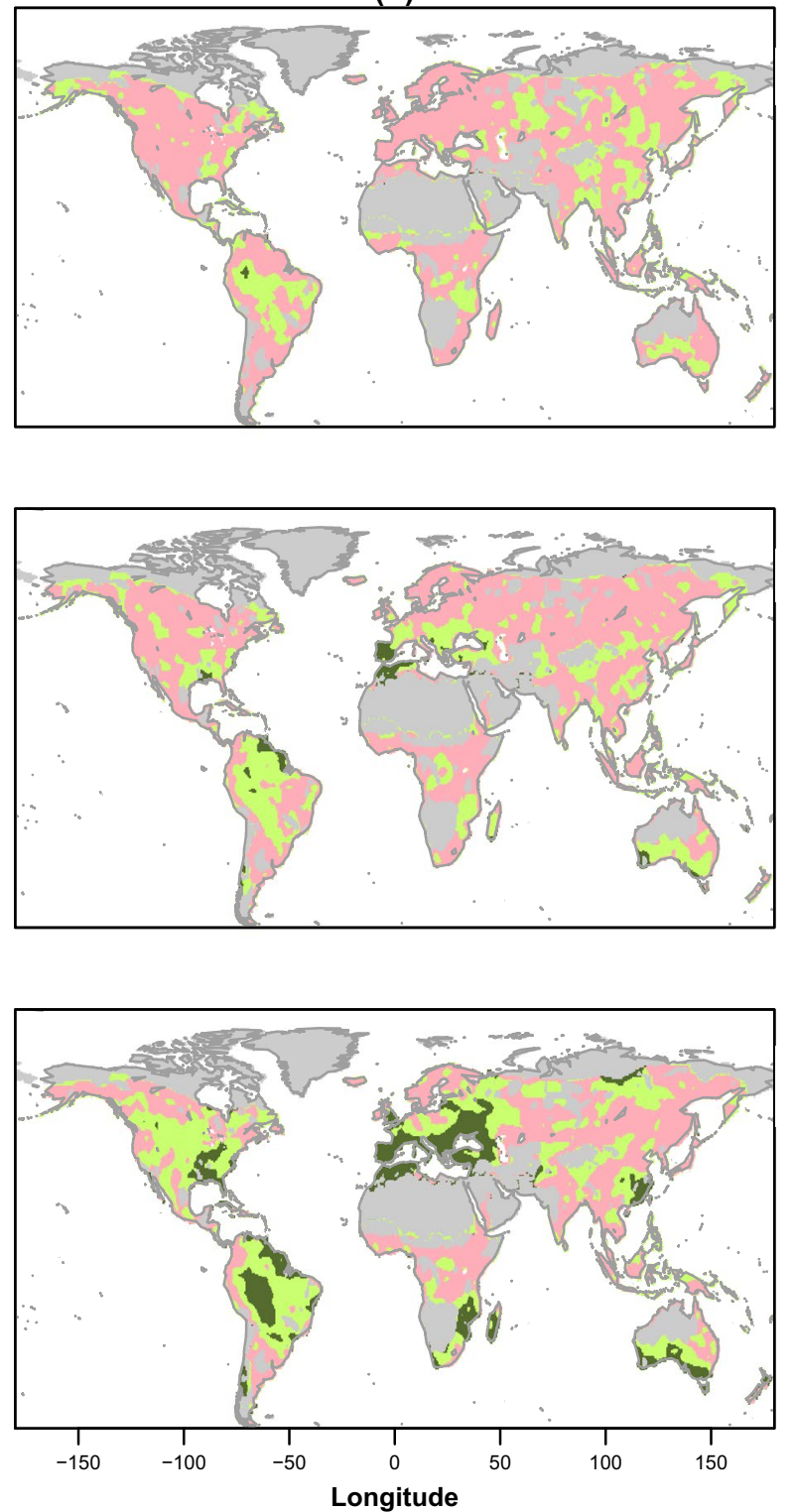

robust changes significant changes non-robust/significant masked territories

Fig. 7 As in Fig. 6 but for the percentage change in CMIP5-EMean between the reference period (1971-2000) and future (2071-2099)

a forced climate change signal that is weaker than the magnitude of internally generated climate variations, as pointed out by Meehl et al. (2009). Indeed, $d H$ changes are not significant and the spatial patterns are similar for the three different concentration pathways in the period 2021-2050, because the climate system response is comparable over the next few decades no matter which RCP is followed (Meehl et al. 2007). This situation becomes more evident for indicators based on precipitation only (than for, e.g. temperature), where even contemporary large-scale forced changes are only marginally separable from internal climate (Zhang et al. 2007; Deser et al. 2012). Indeed, previous studies e.g. Sheffield and Wood (2008), Dai (2011), Orlowsky and Seneviratne (2013) and Spinoni et al. (2015a) have shown that increases in drought impacts during the recent past were not driven by decreased precipitation only, but also by increased evapotranspiration, highlighting that trends in precipitation emerge slowly and their effects on extreme climate events, such as drought, only establish in the longer-term. 


\subsubsection{Projection for the period 2071-2099}

At the end of the century, the magnitude of $d H$ remarkably increases under RCPs 4.5 and 8.5 , as compared to the respective values for the period 2021-2050, and increases at almost all regions from RCP2.6 to RCP8.5 (from top to bottom of Fig. 7a). For example, the estimated magnitude of $d H$ changes for Southern Europe and the Mediterranean region is positive and around 25\% under RCP2.6, increases by $50 \%$ under RCP 4.5 and grows by more than $75 \%$ under RCP8.5. Similarly, while $d H$ is expected to decrease by $25 \%$ under RCP2.6 in almost all central Asia, under RCP4.5 this condition is limited to a minor geographic enclave in the centre of that region, and finally it is expected to wholly increase by at least $25 \%$ under RCP8.5. These results are in line with that of Meehl et al. (2009) and further support the idea that only in the second half of the twenty-first century does the climatological response of precipitation depend significantly on which concentration pathway is followed. Indeed, under RCP2.6, the magnitude of changes is similar to the values registered for the period 2021-2050 at almost all regions, and the spatial patterns of robustness and significance also maintain alike (top of Figs. 6b, 7b). This result was somewhat expected, as the radiative forcing for this RCP reaches its maximum around the middle of the twenty-first century and the occurrence of climate extremes beyond that time should not be significantly aggravated (Taylor et al. 2012).

On the other hand, significant signals of $d H$ changes emerge in a few regions by the end of the century, as averaged over all models under RCPs 4.5 and 8.5 (middle and bottom of Fig. 7b). The analysis of Fig. 7a, b, reveals that differences are statistical significant only for $d H$ increases above $50 \%$ and for the regions where all models agree in the direction of the changes. Indeed, although $d H$ computed with CMIP5-EMean under RCP8.5 climate simulations (bottom of Fig. 7a) is expected to increase by more than $100 \%$ in West African region, these changes are neither robust nor significant. Naturally there is little agreement in the direction of changes from individual models in that region (bottom of Fig. 7b). Despite the reduced number of models used in this study, similar results have been attained by Feng et al. (2014) with simulations from 20 global climate models participating to the CMIP5. They found that mean annual precipitation totals are expected to decrease by more than $30 \%$ in West African region, but there is no majority of models agreeing in the direction of the change. These results suggest that the CMIP5 models collected by the ISI-MIP project are representative of the mean and spread of a larger set of CMIP5 precipitation simulations.

Let us now look in detail at robust and significant $d H$ changes under RCP8.5 for the end of the century. The whole Mediterranean ecosystem, including the areas bordering the Mediterranean Sea, central Chile, the Cape region of South Africa, southwestern and southern Australia, and northern Baja California, display the clearest $d H$ increases, trends which are also found in the CMIP5 analyses of annual precipitation totals in Feng and Fu (2013) and Feng et al. (2014), SPI1 2 in Orlowsky and Seneviratne (2013), and the occurrence of days under drought conditions in Prudhomme et al. (2014). Although meteorological droughts are relatively frequent in the Mediterranean ecosystem, as a consequence of the large inter-annual variability of precipitation Lionello (2012) and long periods with low precipitation Lloyd-Hughes and Saunders (2002), several studies have emphasized that significant drying trends under RCP8.5 might lead to an expansion of semiarid and arid conditions along the Mediterranean Sea, Southern Africa and Australia e.g. (Feng and Fu 2013; Huang et al. 2015). Consequently, the expanse of severe drought events and increasing aridity, along with the rising temperatures and more wildfires, might prompt and exacerbate land degradation processes (Pickup 1998; Reynolds et al. 2007), reduce carbon sequestration and enhance more regional warming by the end of century (Huang et al. 2015). Given that Mediterranean regions have been highly favored and exploited by humans for habitation, agriculture and recreation (Gouveia et al. 2016), and $d H$ changes could result in fundamental shifts in natural ecosystems and human settlements, then there is aggravated risk for food security, and potential for civil conflict and economic decline in the future. For example, Fraser et al. (2013) found that wheat and maize production in the northeastern Mediterranean Sea area is extremely vulnerable to increasing $d H$ in the future, because those regional societies have been reducing socioeconomic efforts to adapt to climate change. Our experiments accentuate the urgent need to develop proactive planning and adaptation strategies for global Mediterranean areas, including the mitigation of climate change impacts on the human populations, but also for maintaining the natural functioning of endemic flora and fauna (Lionello 2012; Vicente-Serrano et al. 2012).

Not surprisingly, we also find robust and significant increases of $d H$ over the entire Amazon by the end of the century, thus reconfirming results from CMIP3 drought analysis in Sheffield and Wood (2008), and corroborating the CMIP5 experiments under RCP8.5 in Dai (2013), Orlowsky and Seneviratne (2013) and Feng et al. (2014), to cite but a few. Several studies agree that the approximate causes are twofold (e.g. Aragão et al. 2007; Marengo et al. 2008): increasing Pacific Sea surface temperatures (SSTs), which intensify El Niño Southern Oscillation and the associated periodic Amazon droughts, and an increase of the Atlantic SST that displaces the inter-tropical convergence zone towards northwest and increases the frequency of historically random droughts. 
As the Amazon basin is less disturbed by antropogenic actions in comparison to the world's large river basins (Tomasella et al. 2011), the series of extreme droughts in recent years provides a unique opportunity to improve our understanding on how pristine environments might function during $d H$ increases by the end of the century. For example, Laurance and Williamson (2001) and Hofer et al. (2012) have reported that long-term drought-induced water stress on intact forests suppresses tree growth, increases tree mortality, and generates leaf litter drying due to increasing canopy openness and understory insolation. Indeed, although the Amazon rainforest has adapted to seasonal and short-term dry spells by strategies such as water uptake by deep roots, the severe drought events of 2005 and 2010 had profound environmental and socioeconomic impacts, and highlighted the sensitivity of its hydrology and ecosystem to prolonged drought conditions (Zeng et al. 2008; Lewis et al. 2011). During the drought event of 2005, (Phillips et al. 2009) evaluated net biomass changes, growth, and mortality of old rainforest, and confirmed that the affected areas lost biomass and reversed a large longterm carbon sink. Consequently, the extremely extended dry seasons in 2005 and 2010, associated with intense natural forest degradation, human induced deforestation and logging, broke out severe wildfires and affected the natural sustainability of the rainforest (Marengo et al. 2008, 2011). As rivers and lakes had the lowest water levels in years, the drought events also provoked large impacts on transportation, fishery, agriculture, generation of hydroelectricity, and affected the health of human populations in the region (Aragão et al. 2007; Marengo et al. 2008; Zeng et al. 2008; Marengo et al. 2011). Therefore, the increase of periodic and random severe drought events by the end of the century might dry the rainforest ecosystem, impact on human activities and change the whole global carbon cycle (Cox et al. 2000; Scholze et al. 2006; Phillips et al. 2009; Lewis et al. 2011). Since the Amazon rainforest process more than twice the rate of anthropogenic fossil fuel emissions (Phillips et al. 2009), then future $d H$ might substantially affect the concentration of atmospheric $\mathrm{CO}_{2}$ and exert a higher feedback on climate change.

Finally, taking the three RCPs together, the clearest signals of wetting are found for the East African region, in agreement with Shongwe et al. (2011), Feng and Fu (2013) and Orlowsky and Seneviratne (2013), and for the core monsoon zone in south Asia-east India and northern region, as previously noted by Feng and Fu (2013), Feng et al. (2014) and Sharmila et al. (2015). However, since GCM simulations are neither robust nor significant for those regions (Fig. 7b), and the percentage changes are always inferior to $-25 \%$ (Fig. 7a), then apparent changes must be interpreted as indicative rather than a future realization of physical reality.

\section{Conclusions}

Recent disasters in developing and developed countries, and the concomitant impacts and personal hardships that resulted have underscored the exposure and vulnerability of all societies to drought. The damages of drought are a product of both the physical magnitude of the hazard and the ability to manage the potential disaster losses, including the systematic efforts to reduce exposure (prevention) and lessen vulnerability (mitigation) of people, livelihoods, and services. Here we focus in the assessment of drought hazard $(d H)$, as characterized by the likelihood of severe precipitation deficits in contemporary and future climates. We followed a rigorous analysis to determine where local assessments should be carried out to improve future adaptation plans and prevention activities, and strengthen multiscale drought risk management policies.

We have analyzed high-resolution monthly precipitation data provided by the ISI-MIP project for three RCPs from five models participating to the CMIP5 project. In particular, we have estimated historical $d H$ and its future changes for middle and end of the twenty-first century from independent drought events computed by means of the WASP-index. With a few exceptions, climate models show increasing global $d H$ between contemporary and both future time periods under all RCPs. On the one hand, the extend of positive $d H$ changes is projected to cover nearly all of the continental areas of North and South America, Europe, West and South Africa, East Asia and Australia. On the other hand, models agree that $d H$ will decrease in some drought hot spot regions of the last decades, such as Central Asia, South and Southeast Asian monsoon regions, and East Africa.

Although the predicted future changes in $d H$ are monotonically increasing and robust across many regions for all RCPs and both future time periods, they are generally not statistically significant. Significance of changes is dependent on many factors, including the magnitude of the change, and the chosen level of significance in the statistical testing used in detecting the impacts of climate change. As this is generally an arbitrary choice, we have used a 95\% confidence level that is ubiquitous in the scientific literaturea 90 or $99 \%$ confidence level could easily be used with important changes in the results. As regards the magnitude of $d H$ changes, our results suggest that significant increases are detectable only after multiple decades, thus confirming that significant changes in intra-annual precipitation regimes only emerge by the end of the century.

Apart from the methodological issues, there are also some uncertainties in $d H$ projections arising from the simulations themselves. Firstly, we have used only five models to represent the uncertainty of the ensemble. Although the uncertainty due to model selection and ensemble member 
size is difficult to quantify, our projections for the future are consistent with the outputs from previous studies based on a different set of models. Secondly, the models themselves may be biased because of inadequacies in the modeled physical processes, parameterizations, downscaling and because of processes that are not included in the modeling. Such biases can generally be evaluated by comparison with observed conditions and this is critical for confidence to be instilled in future projections.

We have shown that models do reasonably well in replicating estimates of twentieth century $d H$ statistics at regional scales, yet with a general under-estimation of $d H$ for subtropical subsidence zones with highly marked precipitation seasonality. The reasons for the differences between the climate models and the GPCCv4-WATCH dataset are unclear at present, but may include model biases in the characteristics of precipitation, especially in the frequency and intensity of individual monthly totals, which impact on the persistence of precipitation anomalies and intensity of $d H$ as computed by the WASP-index. Our experiments are in line with previous results that suggest an overestimation of monthly precipitation totals in arid and semiarid regions by the models participating to the CMIP5 project.

Notwithstanding the uncertainties in future $d H$ changes and some regional inconsistencies between climate models and observations, we can make some general observations regarding the results. The consensus among this set of GCM projections of future climates is that $d H$ will increase relative to the contemporary climate, but will not show statistically significant changes for several decades, indicating that the impacts of climate change will not be felt immediately at regional scales. In general, there is a greater propensity to severe droughts in the Mediterranean ecosystems by the end of the century, which may be especially pertinent when specific impacts on human activities are taken into consideration, such as livestock farming, agricultural yields and household subsistence. This is troublesome, but since water and society are intertwined, then there is a range of drought risk reduction initiatives already available for mitigating its impacts in urban and agricultural regions. Indeed, drought risk management has focused on reducing the impacts of severe droughts in human-dominated environments, where water supply depends on artificial storage in reservoirs and groundwater abstractions that provide water during dry periods.

More worrisome is the fact that $d H$ is shown to increase under all emission scenarios, including the RCP2.6 that projects an increase of $1.5^{\circ} \mathrm{C}$ by the end of the twenty-first century relative to the present day. The implication is that $d H$ will increase, despite future emission reductions, which in turn will increase the time to stabilize atmospheric concentrations of greenhouse gases. Indeed, under higher
RCPs (4.5 and 8.5), the magnitude of the $d H$ changes are expected to be even higher and impact very important natural ecosystems, such has the Amazon, thus exerting higher feedback in the whole carbon cycle. Taken together, our findings point towards the idea that the challenge of drought risk management is not only to establish organizational frameworks and operational arrangements that prepare local populations to $d H$ and its changes, but to progress on global initiatives that prevent drought impacts in natural ecosystems with high biodiversity and capacity to process anthropogenic fossil fuel emissions.

Open Access This article is distributed under the terms of the Creative Commons Attribution 4.0 International License (http:// creativecommons.org/licenses/by/4.0/), which permits unrestricted use, distribution, and reproduction in any medium, provided you give appropriate credit to the original author(s) and the source, provide a link to the Creative Commons license, and indicate if changes were made.

\section{References}

Alfieri L, Burek P, Feyen L, Forzieri G (2015) Global warming increases the frequency of river floods in Europe. Hydrol Earth Syst Sci 19:2247-2260. doi:10.5194/hess-19-2247-2015

Andrade C, Belo-Pereira M (2015) Assessment of droughts in the Iberian Peninsula using the WASP-index. Atmos Sci Lett $16: 208-218$

Aragão LEOC, Malhi Y, Roman-Cuesta RM, Saatchi S, Anderson LO, Shimabukuro YE (2007) Spatial patterns and fire response of recent Amazonian droughts. Geophys Res Lett 34:5

Below R, Grover-Kopec E, Dilley M (2007) Documenting droughtrelated disasters: a global reassessment. J Environ Dev 16:328-344

Biasutti M, Giannini A (2006) Robust sahel drying in response to late 20th century forcings. Geophys Res Lett 33. doi:10.1029/200 6GL026067

Blaikie P, Cannon T, Davis I, Wisner B (1994) At risk: natural hazards, people's vulnerability and disasters. Taylor \& Francis, Boca Raton

Bothe O, Jungclaus JH, Zanchettin D, Zorita E (2013) Climate of the last millennium: ensemble consistency of simulations and reconstructions. Clim Past 9:1089-1110. doi:10.5194/ cp-9-1089-2013

Brasil-MI MMA, MCT (2005) Relatório Final do Grupo de Trabalho Interministerial para Redelimitação do Semiárido Nordestino e do Polígono das Secas. Technical Report. Presidência da República, Brasília, Brasil

Brasil-MMA (2004) National action program to combat desertification and mitigate the effects of drought: PAN-Brazil. MMA Editions ISBN 85-87166-66-2. Environment Ministry, Water Resources Secretariat. Brasília, Brasil

Brooks N, Adger WN, Kelly PM (2005) The determinants of vulnerability and adaptive capacity at the national level and the implications for adaptation. Glob Environ Change 15:151-163

Byun HR, Wilhite DA (1999) Objective quantification of drought severity and duration. J Clim 12:27472756

Campetella CM, Vera CS (2002) The influence of the andes mountains on the south American low-level flow. Geophys Res Lett 29:7-1-7-4. doi:10.1029/2002GL015451 
Cardona O, van Aalst M, Birkmann J, Fordham M, McGregor G, Perez R, Pulwarty R, Schipper E, Sinh B (2012) Determinants of risk: exposure and vulnerability. In: Field C, Barros V, Stocker T, Qin D, Dokken D, Ebi K, Mastrandrea M, Mach K, Plattner GK, Allen S, Tignor M, Midgley P (eds) Managing the risks of extreme events and disasters to advance climate change adaptation. Cambridge University Press, Cambridge, pp 65-108

Carrão H, Naumann G, Barbosa P (2016) Mapping global patterns of drought risk: an empirical framework based on sub-national estimates of hazard, exposure and vulnerability. Glob Environ Change 39:108-124

Carrão H, Singleton A, Naumann G, Barbosa P, Vogt J (2014) An optimized system for the classification of meteorological drought intensity with applications in frequency analysis. J Appl Meteorol Climatol 53:1943-1960

CEC (2007) Impact assessment. Accompanying document from the Commission to the European Parliament and the Council COM (207). Coordinating European Council, Brussels, Belgium

Christensen JH, Boberg F, Christensen OB, Lucas-Picher P (2008) On the need for bias correction of regional climate change projections of temperature and precipitation. Geophys Res Lett. doi:10.1029/2008GL035694. 120709

Cook KH, Vizy EK (2006) Coupled model simulations of the west african monsoon system: twentieth- and twenty-first-century simulations. J Clim 19:36813703

Cox PM, Betts RA, Jones CD, Spall SA, Totterdell IJ (2000) Acceleration of global warming due to carbon-cycle feedbacks in a coupled climate model. Nature 408:184-187. doi: $10.1038 / 35041539$

Dai A (2011) Drought under global warming: a review. Wiley Interdiscip Rev Clim Change 2:45-65

Dai A (2013) Increasing drought under global warming in observations and models. Nat Clim Change 3:52-58. doi:10.1038/ nclimate1633

Dao H, Peduzzi P (2003) Global risk and vulnerability index trends per year (GRAVITY). Technical annex and multiple risk integration Phase IV. UNDP/BCPR, Geneva

Deser C, Phillips A, Bourdette V, Teng H (2012) Uncertainty in climate change projections: the role of internal variability. Clim Dyn 38:527-546. doi:10.1007/s00382-010-0977-x

Dosio A, Paruolo P (2011) Bias correction of the ensembles highresolution climate change projections for use by impact models: evaluation on the present climate. J Geophys Res 116:D16106+. doi:10.1029/2011JD015934

Dosio A, Paruolo P, Rojas R (2012) Bias correction of the ensembles high resolution climate change projections for use by impact models: analysis of the climate change signal. J Geophys Res 117:D17110+. doi:10.1029/2012jd017968

Douville H, Salas-Melia D, Tyteca S (2006) On the tropical origin of uncertainties in the global land precipitation response to global warming. Clim Dyn 26:367385

Dracup JA, Lee KS Jr, Paulson EG (1980) On the definition of droughts. Water Resour Res 16:297-302

Duveiller G, Fasbender D, Meroni M (2016) Revisiting the concept of a symmetric index of agreement for continuous datasets. Sci Rep 6:19401

EEA (2010) Mapping the impacts of natural hazards and technological accidents in Europe. An overview of the last decade. Technical Report 13/2010. European Environmental Agency, Copenhagen

Feng S, Fu Q (2013) Expansion of global drylands under a warming climate. Atmos Chem Phys 13:10081-10094. doi:10.5194/ acp-13-10081-2013

Feng S, Hu Q, Huang W, Ho CH, Li R, Tang Z (2014) Projected climate regime shift under future global warming from multi-model, multi-scenario CMIP5 simulations. Glob Planet Change 112:41-52. doi:10.1016/j.gloplacha.2013.11.002

Foley JA, Ramankutty N, Brauman KA, Cassidy ES, Gerber JS, Johnston M, Mueller ND, O'Connell C, Ray DK, West PC, Balzer C, Bennett EM, Carpenter SR, Hill J, Monfreda C, Polasky S, Rockstrom J, Sheehan J, Siebert S, Tilman D, Zaks DPM (2011) Solutions for a cultivated planet. Nature 478:337-342. doi:10.1038/nature10452

Fraser ED, Simelton E, Termansen M, Gosling SN, South A (2013) vulnerability hotspots: integrating socio-economic and hydrological models to identify where cereal production may decline in the future due to climate change induced drought. Agric For Meteorol 170:195-205. doi:10.1016/j.agrformet.2012.04.008

Giannini A (2010) Mechanisms of climate change in the semiarid African sahel: the local view. J Clim 23:743756

Goddard S, Harms SK, Reichenbach SE, Tadesse T, Waltman WJ (2003) Geospatial decision support for drought risk management. Commun ACM 46:35-37

Gouveia C, Trigo R, Beguera S, Vicente-Serrano S (2016) Drought impacts on vegetation activity in the mediterranean region: an assessment using remote sensing data and multi-scale drought indicators. Planet Chang Glob. doi:10.1016/j. gloplacha.2016.06.011

Gráda CÓ (2007) Making famine history. J Econ Lit 45:5-38

Gulizia C, Camilloni I (2015) Comparative analysis of the ability of a set of CMIP3 and CMIP5 global climate models to represent precipitation in south america. Int J Climatol 35:583-595. doi: $10.1002 /$ joc. 4005

Güneralp B, Güneralp İ, Liu Y (2015) Changing global patterns of urban exposure to flood and drought hazards. Glob Environ Change 31:217-225

Gupta AK, Tyagi P, Sehgal VK (2011) Drought disaster challenges and mitigation in India: strategic appraisal. Curr Sci 100:1795-1806

Hayes M, Wilhelmi O, Knutson C (2004) Reducing drought risk: bridging theory and practice. Nat Hazards Rev 5:106-113

He B, Wu J, Lü A, Cui X, Zhou L, Liu M, Zhao L (2012) Quantitative assessment and spatial characteristic analysis of agricultural drought risk in China. Nat Hazards 66:155-166

Hempel S, Frieler K, Warszawski L, Piontek F (2014) A trend-preserving bias correction the ISI-MIP approach. Earth Syst Dyn 4:219-236. doi:10.5194/esd-4-219-2013

Hofer B, Carrão H, Mcinerney D (2012) Multi-disciplinary forest fire danger assessment in Europe: the potential to integrate longterm drought information. IJSDIR 7:300-322

Huang J, Yu H, Guan X, Wang G, Guo R (2015) Accelerated dryland expansion under climate change. Nat Clim Change 6:166171. doi: $10.1038 /$ nclimate 2837

Huber P, Wiley J, InterScience W (1981) Robust statistics. Wiley, New York

Hulme M (1996) Recent climatic change in the world's drylands. Geophys Res Lett 23:61-64

Iglewicz B, Hoaglin D (1993) How to detect and handle outliers. In: Mykytka EF (ed) The ASQC basic references in quality control: statistical techniques. ASQC Quality Press, Milwaukee, p 78

Insel N, Poulsen CJ, Ehlers TA (2010) Influence of the andes mountains on south American moisture transport, convection, and precipitation. Clim Dyn 35:1477-1492. doi:10.1007/ s00382-009-0637-1

Jacob D, Petersen J, Eggert B, Alias A, Christensen OB, Bouwer LM, Braun A, Colette A, Déqué M, Georgievski G, Georgopoulou E, Gobiet A, Menut L, Nikulin G, Haensler A, Hempelmann N, Jones C, Keuler K, Kovats S, Kröner N, Kotlarski S, Kriegsmann A, Martin E, van Meijgaard E, Moseley C, Pfeifer S, Preuschmann S, Radermacher C, Radtke K, Rechid D, Rounsevell M, Samuelsson P, Somot S, Soussana 
JR, Teichmann C, Valentini R, Vautard R, Weber B, Yiou P (2014) Euro-cordex: new high-resolution climate change projections for European impact research. Reg Environ Change 14:563-578. doi:10.1007/s10113-013-0499-2

Kallis G (2008) Droughts. Annu Rev Environ Resour 33:85-118

Kampragou E, Apostolaki S, Manoli E, Froebrich J, Assimacopoulos D (2011) Towards the harmonization of water-related policies for managing drought risks across the EU. Environ Sci Policy 14:815-824

Keyantash J, Dracup JA (2002) The quantification of drought: an evaluation of drought indices. Bull Am Meteorol Soc 83:1167-1180

Kim H, Park J, Yoo J, Kim TW (2015) Assessment of drought hazard, vulnerability, and risk: a case study for administrative districts in south Korea. J Hydro Environ Res 9:28-35

Knutti R, Sedlek J (2013) Robustness and uncertainties in the new CMIP5 climate model projections. Nat Clim Change 3:369373. doi:10.1038/nclimate 1716

Laurance WF, Williamson GB (2001) Positive feedbacks among forest fragmentation, drought, and climate change in the Amazon. Conserv Biol 15:1529-1535

Lenton TM, Held H, Kriegler E, Hall JW, Lucht W, Rahmstorf S, Schellnhuber HJ (2008) Tipping elements in the earth's climate system. Proc Natl Acad Sci 105:1786-1793. doi:10.1073/ pnas.0705414105

Lewis SL, Brando PM, Phillips OL, van der Heijden GMF, Nepstad D (2011) The 2010 Amazon drought. Science 331:554

Leys C, Ley C, Klein O, Bernard P, Licata L (2013) Detecting outliers: do not use standard deviation around the mean, use absolute deviation around the median. J Exp Soc Psychol 49:764-766

Lionello P (2012) The climate of the mediterranean region: from the past to the future. Elsevier Science, Oxford

Lloyd-Hughes B, Saunders MA (2002) A drought climatology for Europe. Int J Climatol 22:1571-1592. doi:10.1002/joc.846

Lyon B, Barnston AG (2005) Enso and the spatial extent of interannual precipitation extremes in tropical land areas. J Clim 18:5095-5109

Lyon B, Bell MA, Tippett MK, Kumar A, Hoerling MP, Quan XW, Wang H (2012) Baseline probabilities for the seasonal prediction of meteorological drought. J Appl Meteorol Climatol 51:12221237

Marengo JA, Nobre CA, Tomasella J, Oyama MD, de Oliveira GS, de Oliveira R, Camargo H, Alves LM, Brown IF (2008) The drought of Amazonia in 2005. J Clim 21:495-516

Marengo JA, Tomasella J, Alves LM, Soares WR, Rodriguez DA (2011) The drought of 2010 in the context of historical droughts in the Amazon region. Geophys Res Lett. doi:10.1029/2011GL047436. 112703

McKee TB, Doeskin NJ, Kleist J (1993) The relationship of drought frequency and duration to time scales. In: 8th conference on applied climatology, American Meteor Society, Anaheim, Canada, pp 179-184

Meehl G, Stocker T, Collins W, Friedlingstein P, Gaye A, Gregory J, Kitoh A, Knutti R, Murphy J, Noda A, Raper S, Watterson I, Weaver A, Zhao ZC (2007) Global climate projections. In: Solomon S, Qin D, Manning M, Chen Z, Marquis M, Averyt K, Tignor M, Miller H (eds) Climate change 2007: the physical science basis. Contribution of Working Group I to the Fourth Assessment Report of the Intergovernmental Panel on Climate Change. Cambridge University Press, Cambridge, pp 747-845

Meehl GA, Goddard L, Murphy J, Stouffer RJ, Boer G, Danabasoglu G, Dixon K, Giorgetta MA, Greene AM, Hawkins E, Hegerl G, Karoly D, Keenlyside N, Kimoto M, Kirtman B, Navarra A, Pulwarty R, Smith D, Stammer D, Stockdale T (2009) Decadal prediction. Bull Am Meteorol Soc 90:1467-1485. doi:10.1175/ 2009BAMS2778.1
Mishra AK, Singh VP (2009) A review of drought concepts. J Hydrol 391:202-216

Mishra AK, Singh VP, Desai VR (2009) Drought characterization: a probabilistic approach. Stoch Environ Res Risk Assess 23:41-45

Moss RH, Edmonds JA, Hibbard KA, Manning MR, Rose SK, van Vuuren DP, Carter TR, Emori S, Kainuma M, Kram T, Meehl GA, Mitchell JFB, Nakicenovic N, Riahi K, Smith SJ, Stouffer RJ, Thomson AM, Weyant JP, Wilbanks TJ (2010) The next generation of scenarios for climate change research and assessment. Nature 463:747-756. doi:10.1038/nature08823

NCDC (2015) Billion-dollar weather and climate disasters: overview. http://www.ncdc.noaa.gov/billions/overview. Accessed 1 Sept 2016

Nikulin G, Kjellstrm E, Hansson U, Strandberg G, Ullerstig A (2011) Evaluation and future projections of temperature, precipitation and wind extremes over Europe in an ensemble of regional climate simulations. Tellus Ser A 63:41-55. doi:10.1111/j.1600-0870.2010.00466.x

Notz D (2015) How well must climate models agree with observations? Philos Trans R Soc A 373:20140164. doi:10.1098/ rsta.2014.0164

Orlowsky B, Seneviratne SI (2013) Elusive drought: uncertainty in observed trends and short- and long-term CMIP5 projections. Hydrol Earth Syst Sci 17:1765-1781. doi:10.5194/ hess-17-1765-2013

Pascale S, Lucarini V, Feng X, Porporato A, Hasson US (2015) Analysis of rainfall seasonality from observations and climate models. Clim Dyn 44:3281-3301. doi:10.1007/s00382-014-2278-2

Peduzzi P, Dao H, Herold C, Mouton F (2009) Assessing global exposure and vulnerability towards natural hazards: the disaster risk index. Nat Hazards Earth Syst Sci 9:1149-1159

Penalba OC, Rivera JA (2013) Future changes in drought characteristics over southern south America projected by a CMIP5 multimodel ensemble. AJCC 2:173-182

Phillips OL, Aragão LEOC, Lewis SL, Fisher JB, Lloyd J, LópezGonzález G, Malhi Y, Monteagudo A, Peacock J, Quesada CA, van der Heijden G, Almeida S, Amaral I, Arroyo L, Aymard G, Baker TR, Bánki O, Blanc L, Bonal D, Brando P, Chave J, de Oliveira ACA, Cardozo ND, Czimczik CI, Feldpausch TR, Freitas MA, Gloor E, Higuchi N, Jiménez E, Lloyd G, Meir P, Mendoza C, Morel A, Neill DA, Nepstad D, Patiño S, Peñuela MC, Prieto A, Ramírez F, Schwarz M, Silva J, Silveira M, Thomas AS, Steege H, Stropp J, Vásquez R, Zelazowski P, Dávila EA, Andelman S, Andrade A, Chao KJ, Erwin T, Fiore AD, Honorio E, Keeling H, Killeen T, Laurance WF, Peña Cruz A, Pitman NCA, Núñez Vargas P, Ramírez-Angulo H, Rudas A, Salamão R, Silva N, Terborgh J, Torres-Lezama A (2009) Drought sensitivity of the Amazon rainforest. Science 323:1344-1347

Piani C, Weedon G, Best M, Gomes S, Viterbo P, Hagemann S, Haerter J (2010) Statistical bias correction of global simulated daily precipitation and temperature for the application of hydrological models. J Hydrol 395:199-215. doi:10.1016/j. jhydrol.2010.10.024

Pickup G (1998) Desertification and climate change the Australian perspective. Clim Res 11:51-63

Pierce DW, Barnett TP, Santer BD, Gleckler PJ (2009) Selecting global climate models for regional climate change studies. Proc Natl Acad Sci USA 106:84418446

Prudhomme C, Giuntoli I, Robinson EL, Clark DB, Arnell NW, Dankers R, Fekete BM, Franssen W, Gerten D, Gosling SN, Hagemann S, Hannah DM, Kim H, Masaki Y, Satoh Y, Stacke T, Wada Y, Wisser D (2014) Hydrological droughts in the 21st century, hotspots and uncertainties from a global multimodel ensemble experiment. Proc Natl Acad Sci 111:3262-3267. doi:10.1073/pnas.1222473110 
Pulwarty RS (2003) Climate and water in the west: science, information and decision making. Water Resour 124:4-12

Ramankutty N, Evan AT, Monfreda C, Foley JA (2008) Farming the planet: 1. Geographic distribution of global agricultural lands in the year 2000. Glob Biogeochem Cycles 22(GB1003). doi:10.1 029/2007GB002952

Reed S (1997) Crop adaptation to climate change, 3rd ed. UNDP/ UNDRO Disaster Management Training Programme

Reichler T, Kim J (2008) How well do coupled models simulate todays climate? Bull Am Meteorol Soc 89:303311

Reynolds JF, Smith DMS, Lambin EF, Turner BL, Mortimore M, Batterbury SPJ, Downing TE, Dowlatabadi H, Fernández RJ, Herrick JE, Huber-Sannwald E, Jiang H, Leemans R, Lynam T, Maestre FT, Ayarza M, Walker B (2007) Global desertification: building a science for dryland development. Science 316:847851. doi:10.1126/science. 1131634

Rojas R, Feyen L, Dosio A, Bavera D (2011) Improving pan-European hydrological simulation of extreme events through statistical bias correction of rcm-driven climate simulations. Hydrol Earth Syst Sci 15:2599-2620. doi:10.5194/hess-15-2599-2011

Rousseeuw PJ, Croux C (1993) Alternatives to the median absolute deviation. J Am Stat Assoc. doi:10.2307/2291267

Russo S, Dosio A, Sterl A, Barbosa P, Vogt J (2013) Projection of occurrence of extreme dry-wet years and seasons in Europe with stationary and nonstationary standardized precipitation indices. J Geophys Res Atmos 118:7628-7639. doi:10.1002/ jgrd.50571

Russo S, Sterl A (2012) Global changes in seasonal means and extremes of precipitation from daily climate model data. J Geophys Res Atmos. doi:10.1029/2011JD016260

Scholze M, Knorr W, Arnell NW, Prentice IC (2006) A climatechange risk analysis for world ecosystems. Proc Natl Acad Sci 103:13116-13120. doi:10.1073/pnas.0601816103

Seager R, Ting M, Held I, Kushnir Y, Lu J, Vecchi G, Huang HP, Harnik N, Leetmaa A, Lau NC, Li C, Velez J, Naik N (2007) Model projections of an imminent transition to a more arid climate in southwestern north America. Science 316:1181-1184

Sepulcre-Canto G, Horion S, Singleton A, Carraõ H, Vogt J (2012) Development of a combined drought indicator to detect agricultural drought in Europe. Earth Syst Sci 12:3519-3531

Shahid S, Behrawan H (2008) Drought risk assessment in the western part of Bangladesh. Nat Hazards 46:391-413

Sharma TC (1996) Simulation of the Kenyan longest dry and wet spells and the largest rain-sums using a Markov model. J Hydrol 178:55-67

Sharmila S, Joseph S, Sahai A, Abhilash S, Chattopadhyay R (2015) Future projection of Indian summer monsoon variability under climate change scenario: an assessment from CMIP5 climate models. Glob Planet Change 124:62-78. doi:10.1016/j. gloplacha.2014.11.004

Sheffield J, Wood EF (2008) Projected changes in drought occurrence under future global warming from multi-model, multi-scenario, IPCC AR4 simulations. Clim Dyn 31:79-105. doi:10.1007/ s00382-007-0340-Z

Shiau JT, Hsiao YY (2012) Water-deficit-based drought risk assessments in Taiwan. Nat Hazards 64:237-257

Shongwe ME, van Oldenborgh GJ, van den Hurk B, van Aalst M (2011) Projected changes in mean and extreme precipitation in Africa under global warming. Part II: East Africa. J Clim 24:3718-3733. doi:10.1175/2010JCLI2883.1

Sivakumar MV, Stefanski R, Bazza M, Zelaya S, Wilhite D, Magalhaes AR (2014) High level meeting on national drought policy: summary and major outcomes. Weather Clim Extremes 3:126-132

Smakhtin VU, Schipper ELF (2008) Droughts: the impact of semantics and perceptions. Water Pol 10:131-143
Soares WR, Marengo JA (2009) Assessments of moisture fluxes east of the Andes in south America in a global warming scenario. Int J Climatol 29:1395-1414. doi:10.1002/joc.1800

Spinoni J, Naumann G, Carrão H, Barbosa P, Vogt J (2014) World drought frequency, duration, and severity for 1951-2010. Int J Climatol 34:2792-2804

Spinoni J, Naumann G, Vogt J (2015a) Spatial patterns of European droughts under a moderate emission scenario. Adv Sci Res 12:179-186. doi:10.5194/asr-12-179-2015. http://www.adv-scires.net/12/179/2015/

Spinoni J, Vogt J, Naumann G, Carrão H, Barbosa P (2015b) Towards identifying areas at climatological risk of desertification using the Köppengeiger classification and Fao aridity index. Int J Climatol 35:2210-2222

Sterl A, Severijns C, Dijkstra H, Hazeleger W, Jan van Oldenborgh G, van den Broeke M, Burgers G, van den Hurk B, Jan van Leeuwen P, van Velthoven P (2008) When can we expect extremely high surface temperatures? Geophys Res Lett. doi:10.1029/200 8GL034071

Storch HV, Zwiers FW (2003) Statistical analysis in climate research, Virtual Publishing edn. Cambridge University Press, Cambridge

Svoboda M, Hayes M, Wood D (2012) Standardized precipitation index user guide. Technical Report WMO-No. 1090. World Meteorological Organization (WMO), Geneva

Svoboda M, LeComte D, Hayes M, Heim R, Gleason K, Angel J, Rippey B, Tinker R, Palecki M, Stooksbury D, Miskus D, Stephens S (2002) The drought monitor. Bull Am Meteorol Soc 83:1181-1190

Swain S, Hayhoe K (2015) CMIP5 projected changes in spring and summer drought and wet conditions over north America. Clim Dyn 44:2737-2750. doi:10.1007/s00382-014-2255-9

Taylor KE, Stouffer RJ, Meehl GA (2012) An overview of CMIP5 and the experiment design. Bull Am Meteorol Soc 93:485-498. doi:10.1175/BAMS-D-11-00094.1

Tebaldi C, Arblaster JM, Knutti R (2011) Mapping model agreement on future climate projections. Geophys Res Lett. doi:10.1029/2011GL049863. (123701)

Tomasella J, Borma LS, Marengo JA, Rodriguez DA, Cuartas LA, Nobre CA, Prado MCR (2011) The droughts of 1996-1997 and 2004-2005 in Amazonia: hydrological response in the river main-stem. Hydrol Process 25:1228-1242

Traore SB, Ali A, Tinni SH, Samake M, Garba I, Maigari I, Alhassane A, Samba A, Diao MB, Atta S, Dieye PO, Nacro HB, Bouafou KG (2014) Agrhymet: a drought monitoring and capacity building center in the west Africa region. Weather Clim Extremes 3:22-30

UNISDR (2009a) Drought risk reduction framework and practices: contributing to the implementation of the hyogo framework for action. Technical Report. United Nations International Strategy for Disaster Reduction, Geneva, Switzerland

UNISDR (2009b) Global assessment report on disaster risk reduction. Technical Report. United Nations International Strategy for Disaster Reduction, Geneva, Switzerland

Usman MT, Reason CJC (2004) Dry spell frequencies and their variability over southern Africa. Clim Res 26:199-211

Vicente-Serrano SM, Zouber A, Lasanta T, Pueyo Y (2012) Dryness is accelerating degradation of vulnerable shrublands in semiarid mediterranean environments. Ecol Monogr 82:407-428. doi:10.1890/11-2164.1

Wang B, Ding Q (2008) Global monsoon: dominant mode of annual variation in the tropics. Dyn Atmos Oceans 44:165-183. doi:10.1016/j.dynatmoce.2007.05.002

Warszawski L, Frieler K, Huber V, Piontek F, Serdeczny O, Schewe J (2014) The inter-sectoral impact model intercomparison project (ISIMIP): project framework. Proc Natl Acad Sci 111:32283232. doi:10.1073/pnas. 1312330110 
Weedon GP, Gomes S, Viterbo P, Shuttleworth WJ, Blyth E, Sterle H, Adam JC, Bellouin N, Boucher O, Best M (2011) Creation of the watch forcing data and its use to assess global and regional reference crop evaporation over land during the twentieth century. J Hydrometeorol 12:823-848. doi:10.1175/2011 JHM1369.1

Wilhite DA, Glantz MH (1985) Understanding the drought phenomenon: the role of definitions. Water Int 10:111-120

Wilhite DA, Sivakumar MV, Pulwarty R (2014) Managing drought risk in a changing climate: the role of national drought policy. Weather Clim Extremes 3:4-13

Wilhite DA, Svoboda MD, Hayes MJ (2007) Understanding the complex impacts of drought: a key to enhancing drought mitigation and preparedness. Water Resour Manag 21:763-774
Wilks DS (2005) Statistical methods in the atmospheric sciences, 2nd edn. Academic Press, London

WMO (2013) High-level Meeting on national drought policy. Meeting minutes. World Meteorological Organization, Geneva

Zeng NJHY, Marengo JA, Subramaniam A, Nobre CA, Mariotti A, Neelin JD (2008) Causes and impacts of the 2005 Amazon drought. Environ Res Lett 3:9

Zhang X, Zwiers FW, Hegerl GC, Lambert FH, Gillett NP, Solomon S, Stott PA, Nozawa T (2007) Detection of human influence on twentieth-century precipitation trends. Nature 448:461-465. doi:10.1038/nature06025 